\title{
BERGADANAS, CONTINUAS Y MULES. TRES GEOGRAFÍAS DE LA HILATURA DEL ALGODÓN EN CATALUÑA (1790-1830)
}

\section{LLORENÇ FERRER i ALÒS \\ Universitat de Barcelona ${ }^{\mathrm{a}}$}

\begin{abstract}
RESUMEN
En este artículo se constata que en la etapa poco estudiada de la industrialización en Cataluña que tuvo lugar entre 1790 y 1830 hubo tres geografías hiladoras diferenciadas y complementarias: una hilatura manual de bergadana en la Cataluña interior; una hilatura de continua en Manresa y pueblos de los alrededores; y una hilatura de la mule-jenny de madera en Barcelona y en los pueblos de la costa del Maresme. Cada una de estas zonas utilizaba un determinado tipo de energía, producía un modelo de hilo característico, tenía niveles salariales propios, estructuras de tejidos específicas, etc. Las tres zonas coexistieron y se complementaron hasta que en los años treinta se introdujeron nuevas máquinas que provocaron importantes cambios organizativos en todas ellas. Se acaba analizando el caso de Sallent, típico de la hilatura de bergadanas, y el de Manresa, de hilatura de continuas.
\end{abstract}

${ }^{a}$ Departamento de Historia Contemporánea, Facultad de Historia, C/Baldiri Reixach s/n., 08028 Barcelona, llferrer@ub.edu 
Palabras clave: Cataluña, industria textil, tecnología, bergadanas, continuas, mules.

\begin{abstract}
This article verifies the existence of three different and complementary geographies in the 1790-1830 period, a stage in the Catalan industrialization process that has deserved little attention among historians. The first one, of manual spinning by means of an improved jenny -locally named bergadana- in inner Catalonia; a second one of improved water-frame spinning in Manresa and the surrounding villages; and, finally, a third one of wood mule-jenny in Barcelona and some towns of the seaside district of the Maresme. These three areas were characterized by using distinctive power sources and producing different types of thread; they also had different wage levels; but they were complementary until the 1830's when the introduction of new mechanical instruments required important and innovative organization changes. The article ends with two analitical case studies: Sallent as a typical example of manual spinning, and Manresa as a case of water frame spinning.
\end{abstract}

Keywords: Catalonia, Textil Industry, Technology, jennys, mules,water frame. JEL Classification: L67, N63, N94, O14, O33

\title{
1. INTRODUCCIÓN
}

Hasta los años setenta del siglo XX las fábricas de indianas del siglo XVIII habían constituido una pieza en una interpretación continuista del desarrollo de la industria catalana que explicaría la mecanización e industrialización del siglo XIX. Tenía una cierta lógica, ya que se trataba de una manufactura centralizada con utilización de la fibra que más adelante triunfaría. Pero la influencia del modelo histórico inglés, que presuponía que la industrialización era una ruptura con el pasado y, sobre todo, la idea de que no podía haber industrialización sin mercado interior, acabó dejando a las indianas como una simple experiencia que se había expandido gracias al comercio colonial y que acabó fracasando con la pérdida de dicho comercio y la incapacidad del propio mercado interior para asumir la producción. A comienzos de la década de los setenta, así lo escribía J. Fontana (1973, p. 38):

«La industria algodonera ligaba su futuro a la continuación del tráfico colonial y crecía de espaldas a España y a su mercado [...] Cuando perdieron los mercados coloniales y volvieron la mirada España adentro, para 
ver las posibilidades de desarrollo que les ofrecía el mercado nacional, los fabricantes hubieron de percatarse de que aquél en que vivían era un país

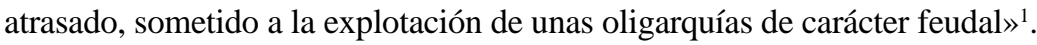

La publicación en el año 1975 del libro de J. Nadal sobre El fracaso de la revolución industrial en España asentaba la citada tesis y databa el inicio de la industrialización en el año 1833, fecha en que los Bonaplata ponían en marcha su máquina de vapor en Barcelona. Estos planteamientos tuvieron muchas consecuencias para la historiografía posterior: primero, la industrialización era el fracaso de las indianas y el resurgimiento después de años de oscuridad de una industria algodonera moderna; segundo, como las indianas se habían desarrollado en Barcelona y la primera máquina de vapor fue instalada en la ciudad condal, la industrialización catalana era un fenómeno barcelonés y el resto de distritos industriales catalanes no se tenían en consideración, y, tercero, las últimas décadas del siglo XVIII y las tres primeras del siglo XIX eran una etapa oscura, sin continuidad. Los estudios de Jaume Torras (1984 y 1987) sobre protoindustrialización y las evidencias incluidas en la obra de Vilar (1964-1968) llevaron a considerar el proceso de crecimiento y modernización económica como un fenómeno que en Cataluña tenía muchas dinámicas y modelos y, después, las aportaciones de A. Sánchez (1988, 1989 y 1992), J. Thomson (1994) y Okuno (1999) han empezado a dar importancia al período que va de 1780 a 1830, en el que se produjeron las transformaciones que explicarán el desarrollo de la industria algodonera a partir de los años treinta.

La industrialización catalana no es un proceso barcelonés, sino la respuesta de las diversas estructuras productivas del territorio a la introducción de una nueva fibra -el algodón- y de nuevas tecnologías². En realidad era la repetición de un proceso que se había dado en distintas épocas y en diversos lugares y que consis-

${ }^{1}$ Esta tesis era formulada de forma casi idéntica por Izard (1973, p. 64). Pronto empezaron a surgir objeciones a este planteamiento. Fue el mismo Fontana quien discutió el papel del comercio colonial en el Coloquio celebrado en Barcelona en el año 1972. Se hacía notar que Cádiz también había vivido del comercio colonial y, en cambio, no había iniciado ninguna evolución hacia la industrialización, lo que llevaba a fijarse en que en Cataluña se producía lo que se exportaba, y en Cádiz no. Estábamos, pues, frente a una realidad diferente. Véase Fontana (1974).

${ }^{2}$ Existe un abundante debate sobre el proceso de difusión de las diferentes tecnologías. Nuestro planteamiento se inserta en las interpretaciones sociales, es decir, que la tecnología se difunde en aquellas zonas en las que encuentra unas condiciones idóneas para ser recibida, al mismo tiempo que la innovación se adapta a las realidades en que debe ser aceptada.La jenny fue adaptada rápidamente en la Cataluña interior porque respondía a las necesidades productivas de la zona. Sobre las diferentes interpretaciones de la difusión tecnológica véase Berg y Bruland (1998), Giannetti, (1994), O’Brien, Griffiths y Hunt, (1996), Rosenberg, (1994) y von Tunzelmann (1993 y 1995). 
tía en el aprovechamiento de las nuevas oportunidades que se presentaban ${ }^{3}$. En Manresa, por ejemplo, se produjo una especialización en los curtidos de piel en el siglo XVII que derivó hacia los tejidos de pañuelos y «menuderías» de seda en el siglo XVIII y hacia los tejidos de algodón en el siglo XIX. Analizando con más profundidad se percibe que la producción de curtidos o tejidos de seda se complementaba con otros muchos negocios de arrendamientos de derechos señoriales, de producción de vino y cualquier otra actividad que pudiera convertirse en negocio. Asimismo, desde un punto de vista social, los artesanos-mercaderes acabaron comprando tierras, convirtieron a sus primogénitos en doctores en Derecho o en Medicina, procuraron conseguir un título de pequeña nobleza y se olvidaron de las actividades productivas. Cuando esto ocurría, otros artesanos tomaban el relevo y se convertían en los individuos dinámicos dispuestos a aprovechar las nuevas oportunidades ${ }^{4}$. El posible estancamiento por arriba se compensaba con un activo dinamismo por abajo. Lo que cambiaba eran las oportunidades, no la disposición para aprovecharlas. Y si los curtidos, la seda y la viña habían sido las del siglo XVIII, el algodón lo era a principios del siglo XIX.

La introducción del algodón encontró unos distritos industriales perfectamente organizados en redes productivas, con recursos humanos especializados y con redes de comercialización bien trabadas que podían incorporarlo perfectamente a su catálogo de actividades productivas si había posibilidad de negocio. La nueva fibra tenía diferencias respecto a otras: no se producía en el país, como la lana o el lino, sino que procedía de la importación y, por tanto, la distribución desde Barcelona se convirtió en un eje principal y de referencia; lo mismo ocurría con los acabados de las empresas de algodón que, y en este caso la tradición de las indianas sí era importante, se realizaban en su totalidad en Barcelona. El algodón reforzó a Barcelona porque era su punto de entrada y distribución y el receptáculo de los tejidos en crudo para ser acabados. Por otro lado, y este es un elemento fundamental, la expansión del algodón iba acompañada de la introducción de nuevas tecnologías que tendían a mecanizar los procesos productivos, que necesitaban más inversiones en capital fijo y, progresivamente, nuevas fuentes de energía que no se encontraban en todas partes. Ello alteraba las pautas que habían funcionado hasta entonces e introducía cambios en muchos frentes.

\footnotetext{
${ }^{3}$ García Espuche (1998) ha escrito un excelente libro en el que plantea el nacimiento de una red de ciudades a finales del siglo XVI, interconectadas entre sí, con una vivísima actividad económica, en las que se desarrollaban una gran cantidad de pequeñas iniciativas que mezclaban producción con comercio y que contribuyeron al crecimiento económico catalán. En el siglo XVIII continuamos encontrando este dinamismo en todo el territorio, y lo que ocurre en el siglo XIX debe verse como la continuación de estas actitudes. Vale la pena reseñar que el libro no argumenta por qué esto se inició a finales del siglo XVI. Tal vez un estudio parecido sobre épocas anteriores encontraría la misma disposición frente a los negocios y aprovechamiento de oportunidades.

${ }^{4}$ Hemos planteado este fenómeno de relevo social en Ferrer i Alòs (en prensa-b).
} 
Era tal el dinamismo de los diferentes distritos industriales que buena parte de ellos entraron a producir hilados y tejidos, incorporando las nuevas tecnologías con una rapidez asombrosa. No hicieron falta campañas de divulgación ni privilegios, las máquinas eran clonadas y mejoradas a toda velocidad por los carpinteros y cerrajeros locales, ocurriendo todo ello porque había plasticidad en el tejido productivo y las nuevas máquinas se adaptaban a las demandas de la localidad.

A principios del siglo XIX se habían desarrollado tres tecnologías hiladoras para la producción de hilados: jennies -de las cuales un tipo evolucionado dio lugar a las bergadanas-, continuas y mules de madera ${ }^{5}$. Las tres tenían ventajas e inconvenientes en cuanto a costes, a necesidades energéticas y al tipo de hilo producido. Cuando empezaron a desarrollarse, nadie sabía exactamente cuál era la mejor ni cuál tenía más futuro, por ello cada zona adaptó aquella que encajaba mejor en su estructura productiva, de tal manera que, en Cataluña, coexistieron con éxito, si hacemos caso de su pervivencia y de las evoluciones posteriores, por lo menos tres maneras distintas de hilar.

Hacia los años treinta del siglo XIX la tecnología de las mules de hierro y, un poco más adelante, de las selfactinas, máquinas mucho más intensivas en capital, rompió esta geografía hiladora e introdujo profundos cambios en la producción de hilados, que tendieron a concentrar los procesos productivos en las nuevas fábricas accionadas con energía hidráulica o de vapor ${ }^{6}$. La relación entre este nuevo modelo y los antiguos condicionó el origen de los nuevos industriales, las formas de organización del trabajo, fruto de la entrada de los antiguos hiladores en las nuevas fábricas, la formación de cuadros directivos y, en definitiva, el aumento de una clase media que fue clave en el proceso de modernización de la sociedad catalana en el siglo XIX ${ }^{7}$.

En este trabajo pretendemos poner énfasis en la coexistencia de los tres modelos de hilatura, definir su geografía, las razones de su aparición y sus características, primero a partir de estadísticas generales y después a partir de datos microhistóricos sobre algunas de las zonas identificadas ${ }^{8}$.

\footnotetext{
${ }^{5}$ Sobre los avances tecnológicos en el algodón, véase Thomson (2004).

${ }^{6}$ Una interesante reflexión sobre el paso de las pequeñas unidades productivas y la utilización de la subcontratación como forma organizativa a la integración vertical en grandes empresas de hilados y tejidos, y sobre la innovación que ello supuso de cara a mejoras en la productividad puede verse en Rosés (1997). También deben consultarse los trabajos de Benaul (1992 y 1995), que analizan el cambio tecnológico y el proceso de modernización de la industria lanera en Terrassa y Sabadell.

${ }^{7}$ Véase la tesis doctoral de García Balañá (2001 y 2004). Esta última referencia alude a la versión publicada de la tesis, aparecida cuando la redacción del presente artículo estaba cerrada.

${ }^{8}$ Estudiaremos solamente el modelo de la bergadana a partir del ejemplo de Sallent y el de las continuas a partir del modelo de Manresa. No entraremos, en cambio, en la hilatura de la mule por no estar presente en la zona estudiada de la Cataluña interior. Sobre el modelo de la mule de madera pueden encontrarse abundantes pistas en García Balañá (2001) y Oliva Ricos (1999).
} 


\section{LOS TRES SISTEMAS DE HILAR EN CATALUÑA}

En Cataluña coexistieron entre 1790 y 1840 tres sistemas diferentes de hilar que se complementaron sin demasiados problemas:

\subsection{La máquina de husos múltiples manual}

En el año 1770 James Hargreaves patentaba la jenny. Hasta entonces una mujer hilaba con un solo huso, mientras que la nueva máquina le permitía hilar con dieciseis husos a la vez. La acción de hilar suponía realizar dos movimientos: dar torsión a la mecha y recoger el hilo en el huso. Esta máquina lo resolvió en dos tiempos: primero se daba torsión y después se recogía9 ${ }^{9}$ Era una máquina manual para cuyo funcionamiento sólo era necesaria una persona; por tanto, resultaba relativamente barata y no requería cambiar la forma tradicional de organizar el trabajo, con la gran ventaja de que un solo trabajador daba movimientos a muchos husos a la vez. El resultado fue la regularidad del producto final y el incremento de la productividad del factor trabajo, pero el hilo que resultaba era frágil y válido solamente para tramas ${ }^{10}$.

Las mejoras en la máquina aparecieron pronto: se cambió la posición de la rueda, que de horizontal pasó a vertical, mucho más práctica para el trabajador, y se fueron añadiendo más husos hasta el límite impuesto por la fuerza física necesaria para moverlos. Según J. Thomson (1994) la primera máquina de hilar apareció en Barcelona en el año 1785 de la mano de Pontet, que era estampador de indianas. Era «una máquina en la qual una sola persona puede hilar treinta y seis hilos de algodón» ${ }^{11}$. Es posible que las máquinas fueran a parar a la Compañía de Hilados el año 1786 y que ésta hiciese funcionar una fábrica con un cierto secretismo entre 1787 y $1792^{12}$. El pretendido secretismo era absurdo porque aparecieron en el interior de Cataluña, buscadas, promovidas y desarrolladas por fabricantes locales. En el Diari de Francisco de Zamora se escribe respecto a Puigcerdá que «de 7 a 8 años de esta parte se han puesto telares de medias y máquinas de hilar algo-

${ }^{9}$ Sobre esta tecnología pueden verse Aspin (1984), Soler Vilabella (1911), Benson (1983), Catling (1970), Jeremy (1981) y Leadbeater (1985). En algunos de estos trabajos se recogen ilustraciones de diferentes máquinas en las que puede observarse su evolución.

${ }^{10}$ Vid. García Balañá (2001, pp. 204-205).

11 Thomson (1994, p. 296). Recientemente se han realizado nuevas aportaciones sobre la introducción de la jenny, siempre desde una perspectiva barcelonesa condicionada por las fuentes de la Junta de Comerç. Véanse al respecto Sánchez Suárez (2000b) y Thomson (2001 y 2003b). Las consideraciones sobre la expansión de la jenny en Cataluña se limitan a su llegada a Berga, desde donde es posible que se expandiera hacia Sallent.

12 Vid. García Balañá (2001, pp. 201-206). 
dón» ${ }^{13}$. Si las máquinas fuesen de hilar se habrían introducido en el año 1781 y sería la primera noticia aparecida en Cataluña, pero no podemos estar seguros, aunque la proximidad de la frontera de Francia lo avalaría. En cambio, en Berga los datos son totalmente certeros y fiables ${ }^{14}$. En la Respuesta de la comarca del Berguedá datada en el año 1789 -aunque el último número es ilegible según los autores de la publicación- se afirma que «de tornos de hilar algodón o lana ay muy pocos o casi ninguno que no lo tenga. Maquinas de hilar algodón nuevamente inventadas ay catorce». Y en el mes de junio de 1790 tenemos la Respuesta de la ciudad de Berga y la evidencia es más explícita: «De tornos de hilar se puede contar uno en cada casa pues la mayor parte de las muchachas se dedican en este trabajo [...] pero si unas treinta máquinas de algodón trabajando una sola muchacha en una de ellas treinta y tantos hilos» ${ }^{15}$. No sólo hay una progresión en cantidad sino que sabemos el número de husos que tenían las máquinas. El próximo paso que conocemos se dio en Cardona en el año 1792, cuando Manuel Flotats y Salvador Pallerolas, socios de una fábrica de indianas local, pidieron a la Junta de Comercio el monopolio para distribuir una máquina de hilar de 78 husos, gracias a la colaboración del inglés Bernard Young ${ }^{16}$. Pero mientras se hacía esta petición, Martí Vinyes, carpintero y fabricante de Berga, se comprometía a construir ocho máquinas de hilar de 75 a 80 husos como la de Manuel Flotats en Cardona ${ }^{17}$. Los husos habían aumentado y las máquinas eran copiadas por carpinteros y herreros locales expandiéndose con gran celeridad. Esta precocidad de la comarca justifica el hecho, conocido desde la aportación de Soler Vilabella (1911), de que, en Cataluña, la jenny mejorada de 120 husos recibiese el nombre de bergadana. Según A. Solá (1995, 1997 y 2002), esta última configuración se alcanzó entre 1800 y 1810.

Hilar con máquina era, de hecho, la última fase del proceso de hilatura, ya que el algodón tenía que prepararse antes. El trabajo de Soler Vilabella (1911, pp. 39 y ss.) sobre la bergadana aporta también información sobre cómo se hacían otros trabajos complementarios:

«El cotó es rebia en saques tal com se collia portant encara la grana o llavor, s'espolsava y rebatia com fan amb la llana els matalassos, s'adobava amb sabó moll y en aquestes condicions es portava als carders, si el filandor no tenia cardes, de quins es recullen en paquets d'un pes fixo dits pesalls [...] A Berga no es coneixia el batan obridor (llop o diable);

\footnotetext{
${ }^{13}$ Véase Zamora (1973).

${ }^{14}$ Vid. Serra y Ferrer (1985).

15 Respuesta de Berga, VI-1790, Mn. 1680, Microfilm Departament d’Història Contemporània, Universitat de Barcelona.

16 Véase Thomson (1994, pp. 302-305).

${ }^{17}$ Registre de la Propietat de Berga. Comptaduria d'Hipoteques, 1792, fol. 195. Documento citado por A. Solá en el curso «Els orígens de la industrialització a Cataluña», Centre d’Estudis del Bages, 1994.
} 
estobava y espolsava el cotó, batentlo ab bastons de freixa sobre una especie de engraellat inclinat, apoyat a una pared, fet amb barrots de fusta dura, de secció triangular [...] amanintlo ab l'aigua savorosa o mida que es rebatia. Aquest engraellat es coneixia per rebatador».

Después de batir el algodón se iniciaba el cardado, es decir el proceso de poner las fibras en paralelo, «que requerien major força, generalment de caballeries o hidráulica» y, finalmente, se convertía en mecha «aixó s'aconseguia amb un torn de filar però amb les cames més altes per treballar-hi dret, aixís com en lo de filar se fa assentat. Al costat del tornet hi havia una mica de postadeta y ahont se posaven les cardades y d'allí s'anava prenent per filar». Después, la mecha, con una ligera torsión obtenida en el tornet, se llevaba a la máquina de hilar, y de aquí de nuevo al tornet para producir los rodetes que tenían que alimentar las lanzaderas de los telares.

De este proceso se desprende que, tan importante como la máquina de hilar de husos múltiples, fue la mecanización del cardado, a la cual se ha prestado muy poca importancia. El cardado necesitaba más fuerza física y la utilización de energía no humana -hidráulica o caballerías- resolvió la situación, aunque ello suponía una inversión mayor en capital fijo. En el año 1789 no había en Berga ninguna máquina de cardar según las Respuestas de Zamora. Josep Ferrer Vidal (1874, p. 38) escribía casi un siglo después que, en el año 1790, «funcionaban ya en Cataluña la máquina para hilar tramas y también las de cardar con cilindros». En el mes de enero de 1791 la fábrica de la Compañía de Hilados de Barcelona substituyó las cardas manuales por «una màquina de cardar»-seguramente una carda de tambor ${ }^{18}-\mathrm{y}$ M. Flotats de Cardona y S. Pallarola de La Seu d’Urgell, cuando pedían el privilegio de exclusividad para nuevas máquinas en el año 1792, lo hacían también para una nueva máquina de cardar «la primera es superior a todas las conocidas hasta ahora en Cataluña por la equidad y perfección con que se carda en ella» ${ }^{19}$. A diferencia de las bergadanas, las cardas necesitaban un esfuerzo mayor, lo que hizo que los varones se ocupasen del cardado, y la regularidad de su movimiento las hizo propensas a la automatización utilizando energía hidráulica o energía animal. La fase del cardado se segregó de la hilatura y aparecieron fábricas especializadas en esta tarea que utilizaban la energía hidráulica -por lo menos en Berga y Sallent- y que se dedicaban a abastecer de algodón cardado a la extensa red de hiladores ${ }^{20}$. Eran una pieza clave en este modelo de hilatura manual, y también el más desconocido.

${ }^{18}$ Puede verse una descripción de esta máquina en Ronquillo (1851-1857) y Reddy (1984).

${ }^{19}$ Citado por Maluquer de Motes (1994, p.104).

${ }^{20}$ Estamos en condiciones de afirmar que en Berga y Sallent el algodón cardado procedía de las fábricas que aprovechaban la energía hidráulica de la riera de Metge en el primer caso y del Llobregat en el segundo -vid. Ferrer i Alòs (1999)- pero no sabemos dónde se cardaba el algodón en otras ciudades en que la hilatura de bergadanas también fue importante, como en Igualada, Capellades, Roda de Ter o Reus, aunque suponemos que se utilizaban caballerías. El gran número de caballerías en Igualada parece sugerir esta solución. 
En el año 1796, en una revisión del privilegio otorgado a Flotats y Pallarola, se defendía la nueva máquina de hilar y se decía:

«agrega la máquina una sencillez suma, fácil composición y manejo, coste escaso [...] y cómoda colación y transporte; de manera que la madre de familia pueda sin separarse de sus cuydados domésticos, y por pocas que sean sus facultades, tener propia y usar en su habitación esta máquina tal vez más apreciable» ${ }^{21}$.

Se presuponía que la estructura organizativa del trabajo, basado en una gran cantidad de hiladoras que trabajaban en su casa hilando con sus hijos para un paraire que organizaba el proceso, no cambiaría. Era lógico que se pensase que cada hiladora sustituiría su torno manual por una máquina que tenía un coste escaso, pero desde el primer momento la evolución no tomó en esta dirección, ya que las nuevas máquinas de hilar fueron adquiridas por hombres que creaban su propio taller desde donde organizaban el proceso productivo utilizando mujeres y niños para su funcionamiento. Las mujeres dejaron de trabajar en casa a su aire como habían hecho hasta entonces para pasar a trabajar en talleres, y los hombres, como los antiguos obradores artesanos, pasaron a controlar los nuevos procesos productivos. Estos talleres, situados en los bajos de las casas, acogieron más de una máquina de hilar y, en la mayoría de los casos, también telares.

¿Qué tipo de hilo se hilaba? Hemos citado anteriormente que las máquinas de hilar de husos múltiples elaboraban de forma regular hilados que eran útiles para tramas y no tanto para urdimbres. Si las máquinas no producían urdimbres, ¿de dónde salían éstas? El tema tiene sus ambigüedades ya que no podemos afirmar de forma contundente que las susodichas máquinas sólo sirvieran para un tipo de hilado, aunque parece que así era la tendencia general. Ferrer Vidal $(1874$, p. 38) muestra esta ambigüedad cuando habla de estas máquinas: «no solamente hilaron tramas como en Inglaterra, sino también buenos urdimbres [...] la máquina bergadana [...] producía buenos o muy regulares hilos para tramas, y también para urdimbre». Todo parece indicar que, aunque esta máquina rindiera mejor en la producción de tramas, también podía fabricar urdimbres, lo que aseguraba la producción de tejidos. Esto no ocurría con la continua o throstle que solo hilaba urdimbres y necesitaba de las máquinas de hilar manuales para producir tramas, lo que ayuda a explicar la coexistencia de modelos diferentes de hilatura, como veremos más adelante. De todas maneras, el hecho de que la destreza de la hiladora tuviera un papel importante en la hilatura con esta máquina también puede explicar que el hilado que se producía tuviese calidades distintas, lo que no ocurrirá en máquinas más automatizadas en que la destreza humana jugaba un papel más secundario.

${ }^{21}$ Citado por Thomson (1994, p. 305). 
La primera gran expansión del algodón se verificó mediante este modelo: cardado mecánico en edificios específicos, máquinas de hilar de husos múltiples y telares manuales que sustituían a las redes laneras y lineras asentadas en el territorio, y tuvo su especial desarrollo en las comarcas de la Cataluña interior -Berguedá, Bages, Osona, Anoia y Garrotxa- entre 1790 y 1840 . Este fenómeno ha sido muy poco considerado en las explicaciones de la industrialización catalana y es clave para entender la expansión industrial posterior en aquellas zonas.

\subsection{La continua de hilar o throstle}

La máquina de hilar de Arkwright llegó a Barcelona de la mano de dos ingleses, John Waddle y Josep Caldwell, que habían intentado hacer fortuna en Francia y que acabaron ofreciendo sus servicios al embajador de España en París ${ }^{22}$. En el año 1789 el Gobierno autorizó su desplazamiento a Barcelona para poder mostrar las nuevas máquinas, pero en el año 1791 se marcharon sin haber logrado que los fabricantes catalanes hiciesen ninguna adquisición. El Gobierno había montado fábricas en Ávila y Madrid y parece que fue en estas fábricas donde se instalaron las primeras continuas y desde donde llegaron realmente a Barcelona ${ }^{23}$.

¿Cuándo se extendió por Cataluña? J. Ferrer Vidal (1874, p. 38) afirma que se introdujo en el año 1791 «propia solo para hilar urdimbres». Las primeras experiencias reales sitúan las máquinas en Tarragona y en Barcelona y Olot en el año 179324; en este último caso, los innovadores son unos fabricantes locales y Pablo Serrano, un maquinista de Ávila, al que más adelante encontraremos en Manresa. Sánchez Suárez (1989, pp. 97-98) argumenta que las continuas comenzaron a generalizarse entre 1803 y 1807, que es cuando empezaron a solicitarse concesiones de agua en los ríos catalanes. El Diccionario Geográfico Universal (1834-1835, Tomo V, p. 831) es más preciso:

«[...] en 1800 se establecieron fábricas de hilados en grande con las máquinas inglesas llamadas throstle o continuas para dar urdimbre, que inventó el mismo inglés High con sistemas enteros de máquinas para cardar, preparar e hilar el algodón para urdimbres al estilo de las que estableció en Inglaterra sir Richard Arkwright el 1775 [...] En el año 1801 se estableció la primera en Manresa y en 1806 se veían ya grandes establecimientos de hilados.»

${ }^{22}$ Sobre esta máquina puede verse Benson (1983) y Fitton (1989). En este último trabajo (pp. 14 y 19) aparecen varias reproducciones de continuas.

${ }^{23}$ Véanse Martín García (1989) y Thomson (1994, pp. 298 y ss.).

${ }^{24}$ Vid. Sánchez Suárez (2000b, p. 170) y Thomson (1998 y 2003a). 
Probablemente esta primera instalación correspondía a las fábricas de las Fontetes y de Cal Serrano que la sociedad Codina, Dalmau, Martí y Serrano tenían en el torrente de Sant Ignasi de Manresa, y que habían puesto en funcionamiento aquel año, como veremos más adelante. Pablo Serrano había sido el socio constructor de las máquinas en las fábricas de Manresa.

La continua era una máquina que hilaba con un sistema diferente. Los dos tiempos de la bergadana -torcer la mecha y después bobinar el hilado- se sustituían por un movimiento continuo en el que torsión y bobinado se producían de forma instantánea. Era una máquina más productiva que la jenny y que estaba pensada para que funcionara con energía hidráulica, lo que requería una instalación más costosa y una inversión de capital mucho más elevada. Asimismo, esta nueva máquina implicaba la mecanización de todo el proceso de hilado e iba acompañada de «manuares» y mecheras que preparaban el hilo para las continuas y que también necesitaban ser accionadas con energía hidráulica.

No parece que las continuas hiciesen una competencia directa a la bergadana, ya que producían hilados que sólo se podían utilizar como urdimbres. En este caso estamos ante una tecnología complementaria o que, dicho de otra manera, necesitaba un apoyo de máquinas sencillas para la producción de tramas. Todo ello quizá pueda explicar la coexistencia de tecnologías con productividades bien diferentes, pero esto se tendría que demostrar a partir de contabilidades de estas unidades productivas. La ciudad de Manresa y los pueblos adyacentes constituyeron el centro más avanzado en la implantación de esta maquinaria, de manera que todas las fábricas que utilizaban energía hidráulica poseían este tipo de tecnología. Esta localización tenía otro sentido: el sector de la cintería de Manresa empezaba a utilizar el algodón de forma masiva en sus famosas vetes y necesitaba urdimbre para sus telares manuales de remo, lo que explicaría la participación de cinteros en la construcción de estas fábricas ${ }^{25}$. El partido judicial de Manresa concentrará la mayor parte de la citada tecnología.

Estas máquinas recibirán el nombre de maquinas inglesas, con el que suelen aparecer en la documentación.

\subsection{Las mule-jennies}

A menudo se suele plantear el proceso de industrialización como una sucesión de tecnologías, cada vez más intensivas en capital y sustituyéndose unas a otras. La mule suele mostrarse como una tecnología que desplazó a las bergadanas y, en cambio, hoy podemos afirmar que no fue así. El error suele comenzar cuando se piensa que las mules siempre han tenido la misma configuración, lo cual no es

${ }^{25}$ Vid. Ferrer i Alòs (1994a). 
cierto. Las máquinas evolucionan aunque mantengan el mismo nombre y el mismo principio tecnológico: así, la mule de madera y de pocos husos, que caracterizaba la primera etapa, era diferente de la mule de hierro, que necesitaba más energía y que se generalizó en los años cuarenta del siglo XIX.

La mule era un perfeccionamiento de la jenny. Ésta realizaba dos movimientos de forma separada: la torsión de la mecha hasta convertirla en hilo y, después, la recogida del hilo en el carrete; la mule mecanizó el primero y lo perfeccionó dando más calidad al hilado resultante, pero el retorno del carro, bobinando el hilo, tenía que hacerlo la hiladora de forma manual ${ }^{26}$. El nombre de la máquina hacía alusión a este carácter mixto. Tenía ventajas respecto a la primitiva continua: no era tan intensiva en energía, podía ser movida sin demasiada dificultad por caballerías e hilaba tanto urdimbres como tramas, especialmente estas últimas, y de números más altos. Se calculaba que una continua consumía el doble de energía que una $m_{\text {mule }}{ }^{27}$. Era una máquina ideal para zonas en las que no abundaba el agua y se necesitaban números altos para tejidos de más calidad.

J. Ferrer Vidal (1874, p.39) señalaba la fecha de 1805 como el año de la introducción de las mules accionadas por caballerías y ruedas hidráulicas, pero hay cierta confusión. Para algunos autores, la máquina de Crompton llegó el año 1805 de la mano de una empresa formada por el comerciante Jean de Cramp bajo la protección del Conde de Cabarrús ${ }^{28}$. Otros atribuyen su llegada a Jacint Ramon y otros estampadores barceloneses a una fecha anterior, pero parece que existe confusión con otros tipos de máquinas ${ }^{29}$. Sánchez Suárez (2000b, pp. 173-175) también sitúa entre 1806 y 1807 su entrada y su generalización progresiva debido a las limitaciones energéticas de Barcelona. Tal vez el hecho de que fueran unos franceses los que introdujeron las máquinas llevó a que fuesen conocidas con el nombre de «máquinas francesas» en estos años en contraposición a las continuas o «máquinas inglesas».

Las tres tecnologías hiladoras, con sus ventajas y sus inconvenientes, se desarrollaron en buena parte de Cataluña, de tal manera que se pueden establecer tres geografías específicas. Una tecnología no acabó con la otra, sino que unas y otras se complementaron durante unos cuantos años -en urdimbres, tramas, números altos o bajos- aprovechando las ventajas que cada una ofrecía. En el Diccionario de 1834-1835 (p. 732) se escribía que «las jennys se empiezan a llamar bergadanas aumentando sus husos hasta 120, cuya hilaza hasta el $\mathrm{n}^{\circ} 25$ se emplea en los tejidos planos con tan buen éxito como el de las mule-jennys con la

\footnotetext{
${ }^{26}$ Véase Catling (1970, pp. 25-71).

27 Vid. García Balañá (2001, pp. 265-276).

${ }^{28}$ Así, Thomson (1994, p. 313).

${ }^{29}$ Véanse Izard (1973), Nadal (1975) y Soler Vilabella (1911).
} 
ventaja de que aquellas solo cuestan la 1/6 o $1 / 7$ parte» $^{30}$. Las ventajas de una tecnología sobre otra no sólo se miden por la productividad sino por aspectos cualitativos que no siempre se tienen en consideración y que acaban siendo muy importantes -formación de la mano de obra, costes laborales, experiencia en el distrito industrial, tipo de producto, especializaciones, etc. Si no fuera por eso, no se podría entender por qué coexistieron -parece que con eficiencia si consideramos la evolución posterior- tecnologías que tenían una productividad tan diferente.

\section{LAS GEOGRAFÍAS DE LOS TRES SISTEMAS DE HILAR}

Pascual Madoz publicó en su Diccionario (1845-1850, Vol. III, pp. 456-485) datos exhaustivos sobre la industria algodonera catalana resumidos por partidos judiciales, datos que proceden en su mayoría de la publicación de Esteban Sayró (1842) recogidas en el año 1839. Estos datos se refieren al número de husos y telares de cada partido judicial, al tipo de máquinas de hilar, a los motores que se utilizaban para moverlas, a la mano de obra que ocupaban, a la producción, a las piezas de tejidos, etc. A partir de estas variables podemos reconstruir la geografía de los tres tipos de hilatura ${ }^{31}$.

Estos datos presentan tres tipos de problemas: a) el criterio de agrupación en partidos judiciales puede darnos la impresión de territorios homogéneos en una determinada actividad cuando a menudo eran determinadas localidades dentro del partido judicial las que tenían aquella actividad textil; b) su fiabilidad estadística, cuestionada por las posibles ocultaciones en las declaraciones y por la no contabilización de determinadas actividades, como por ejemplo los telares manuales esparcidos en pequeños pueblos ${ }^{32}$, y c) el hecho de que las nuevas tecnologías mules de hierro- y las nuevas formas de producir energía -máquina de vapor- ya hiciera por lo menos diez años que se habían introducido en Cataluña cuando se recogieron los datos, lo que hace que en la estadística haya incorporada informa-

${ }^{30}$ Esta cita no aclara cuándo las máquinas empezaron a llamarse bergadanas, simplemente que habían llegado a los ciento veinte husos, y la noticia de su ventaja con respecto a las mules de madera.

${ }^{31}$ Hay una polémica sobre si los datos de bergadanas reflejan la realidad o si, por el contrario, estaban sobrevalorados por los problemas arancelarios de los fabricantes: vid. Figuerola (1849, pp. 311-314). En realidad, este argumento nos importa poco. Tal vez en este momento empezasen a entrar en decadencia, pero no hay duda que unos años antes esta estructura era una realidad, y esto es lo que nos interesa mostrar en este momento.

${ }^{32}$ Madoz era consciente de ello y escribía: «Es indudable, como diremos más adelante al tratar de la industria como riqueza imponible que cuando el gobierno pide las declaraciones correspondientes para averiguar el estado de las fábricas, se hacen grandes ocultaciones por el recelo de que se aumenten los impuestos. El mismo señor Sayró consignó esta verdad aumentando sobre las manifestaciones hechas un $4 \%$ en los hilados y un $10 \%$ en los tejidos». P. Madoz (1845-1850, Vol. III, p. 464). 
ción que no se corresponda con las formas de hilar antes mencionadas, de manera que, al presentarse los datos agregados, pueden producirse distorsiones. Esto ocurre especialmente en Barcelona, en Mataró y en Vilanova, donde se habían empezado a levantar fábricas accionadas a vapor, pero también en Sallent, donde algunas de las antiguas fábricas que se dedicaban al cardado del algodón habían introducido ruedas hidráulicas, habían cambiado la tecnología, e hilaban con mules. No es posible desagregar los datos, por lo que hay que tener muy en cuenta esta cuestión ${ }^{33}$.

La hilatura de la bergadana era la que estaba extendida por más comarcas, aunque se concentraba en cuatro partidos judiciales del interior de Cataluña: Igualada -el 36\% de las máquinas-, el Berguedá -19,8\%-, Manresa ${ }^{34}-11,7 \%$ - y Vic -11\%-; bastante más lejos quedaba Olot, con el 5,9\%. En estos partidos judiciales casi todo el hilo se hilaba con bergadanas, que superaban ampliamente el $90 \%$ del total de máquinas: en Berga suponían el 99,1\%; en Igualada el 99,4\%; en Vic el 94,5\%, y en Olot el 97,5\%. En Manresa suponían el 75,7\% del total, debido a que era también un partido de continuas, como veremos. Por tanto, podemos decir que estos partidos constituían la zona de hilatura con bergadanas, que constituían el $84,4 \%$ de las máquinas. Sabemos también que funcionaban con energía humana, y así se observa en el Cuadro 2 donde se analizan los tipos de motor que accionaban las máquinas. Los porcentajes de «motor operarios»-Cuadro 2- y máquinas -Cuadro 1- son casi idénticos en estos partidos, lo que indica que cada máquina era accionada por la fuerza humana de un individuo: Igualada concentraba el 36\% de las bergadanas y el 37,8\%, de los motores humanos; Berga el 19,8\% y 19,3\%; Manresa el 11,7\% y el 12,3\%, y Vic el 11\% y el 10,9\%. Era, pues, una tecnología que no utilizaba ni la energía animal ni la hidráulica.

${ }^{33}$ La visión que presentamos puede ser acusada de estática, ya que no analizamos la dinámica de estas geografías. La geografía de la bergadana y la de las continuas se formó entre finales del siglo XVIII y la primera década del siglo XIX. Donde seguramente se produjo un proceso de sustitución fue en Barcelona, ya que las mules se expandieron más tarde. Los datos de 1850 proporcionados por Graell (s.a.), cuando las nuevas máquinas de hilar se introducían a toda velocidad, aún constatan la supervivencia de las antiguas geografías, aunque con matices debido a los cambios que se estaban introduciendo. El 50,2\% de los husos de mules se localizaba en Barcelona y el $11,7 \%$ en el Maresme -la fuente no distingue entre viejas mules de madera y nuevas mules de hierro-; el 40,9\% de los husos de continuas se localizaban en Manresa y sus alrededores, seguida de Barcelona con el 27,7\%. Las bergadanas habían desaparecido totalmente de Berga -difícil de creer la rotundidad- y era en Igualada donde mejor resistían, concentrándose allí el 75,7\% de los husos. En el Bages se concentraban el 13,6\% de este tipo de husos. En Igualada estaban activos el 60,4\% de los husos de 1841. Es totalmente necesaria una investigación sobre el caso de Igualada: si la bergadana se mantuvo tanto tiempo es porque producía hilados rentables, y sólo la falta de agua llevó a sus fabricantes a la emigración a Barcelona, Reus o Manresa.

${ }^{34}$ A pesar de que en el partido judicial de Manresa había una concentración importante de bergadanas, éstas no se concentraban en la ciudad sino en algunos pueblos como Sallent, Santpedor o Balsareny. Véase Guía (1842, pp. 69-112). 


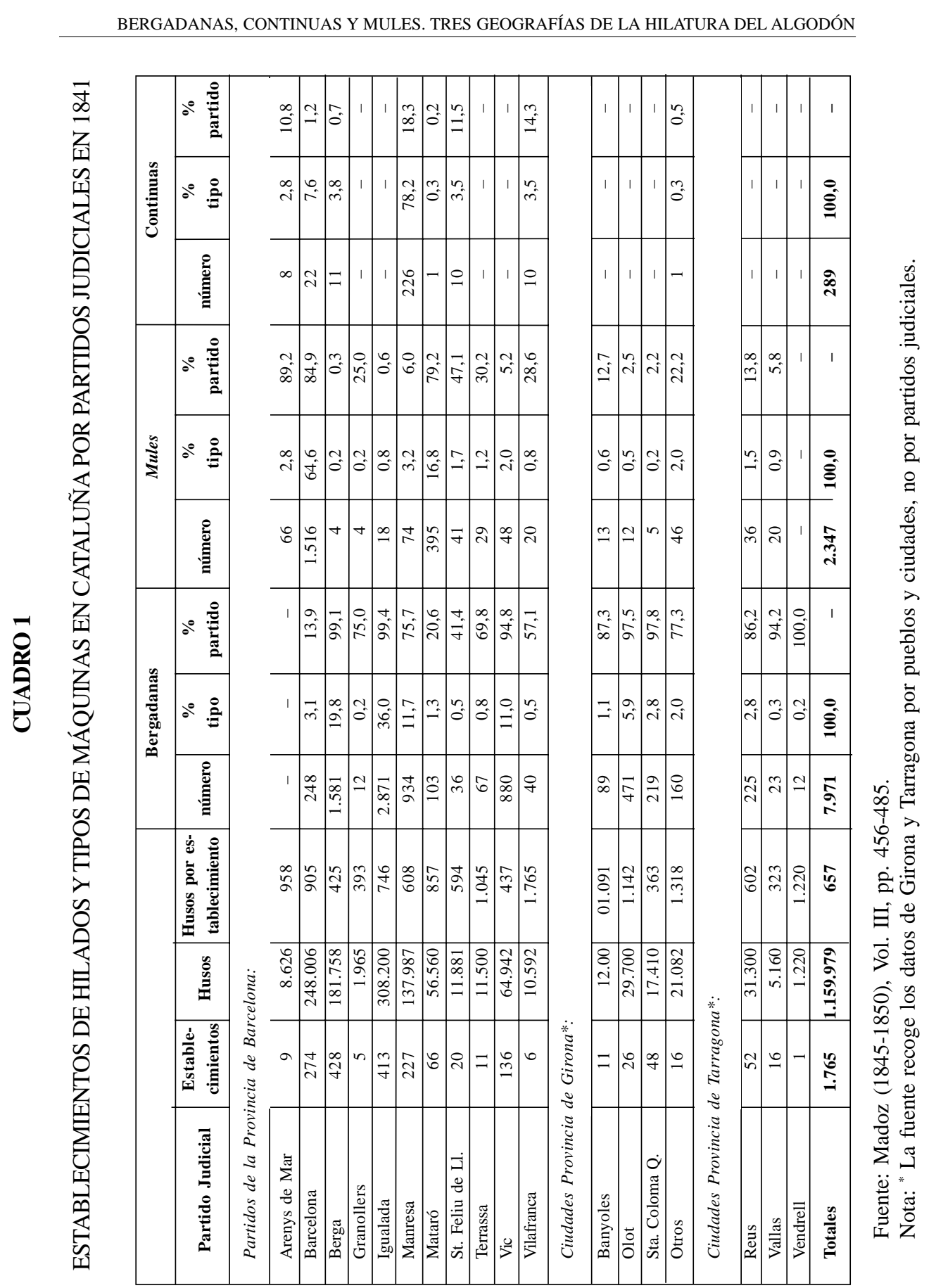




\section{CUADRO 2}

MOTORES UTILIZADOS POR LOS ESTABLECIMIENTOS DEDICADOS A LA HILATURA DEL ALGODÓN EN 1841

\begin{tabular}{|c|c|c|c|c|c|c|c|c|}
\hline \multirow[t]{2}{*}{\begin{tabular}{|l|} 
Partido \\
Judicial \\
\end{tabular}} & \multicolumn{2}{|c|}{$\begin{array}{c}\text { Energía } \\
\text { hidráulica }\end{array}$} & \multicolumn{2}{|c|}{ Vapor } & \multicolumn{2}{|c|}{ Caballerías } & \multicolumn{2}{|c|}{$\begin{array}{r}\text { Energía } \\
\text { humana }\end{array}$} \\
\hline & c.v. & $\%$ & c.v. & $\%$ & & $\%$ & & $\%$ \\
\hline \multicolumn{9}{|c|}{ Partidos de la Provincia de Barcelona: } \\
\hline Arenys de Mar & 10 & 1,8 & - & - & 36 & 3,0 & - & - \\
\hline Barcelona & 10 & 1,8 & 229 & 79,2 & 659 & 55,8 & 203 & 2,4 \\
\hline Berga & 70 & 12,9 & - & - & 20,2 & 1.604 & 19,3 & \\
\hline Granollers & - & - & - & - & 4 & 0,3 & 12 & 0,2 \\
\hline Igualada & 13 & 2,4 & - & - & 150 & 12,7 & 3.148 & 37,8 \\
\hline Manresa & 238 & 43,8 & - & - & - & - & 1.036 & 12,4 \\
\hline Mataró & - & - & 32 & 11,1 & 197 & 16,7 & 132 & 1,6 \\
\hline $\begin{array}{l}\text { St. Feliu de } \\
\text { Llobregat }\end{array}$ & 48 & 8,8 & - & - & - & - & 36 & 0,4 \\
\hline Terrassa & 20 & 3,7 & 8 & 2,8 & 1 & 0,1 & 61 & 0,7 \\
\hline Vic & 40 & 7,4 & - & - & 26 & 2,2 & 911 & 10,9 \\
\hline Vilafranca & - & - & 20 & 6,9 & 7 & 0,6 & 50 & 0,6 \\
\hline $\begin{array}{l}\text { Provincia de } \\
\text { Girona* }\end{array}$ & 94 & 17,3 & - & - & 23 & 1,9 & 933 & 11,2 \\
\hline Tarragona* & - & - & - & - & 77 & 6,5 & 204 & 2,5 \\
\hline Totales & 543 & 99,9 & 289 & 100,0 & 1.182 & 100 & 8.330 & 100,0 \\
\hline
\end{tabular}

Fuente: Madoz (1845-1850), Vol. III, pp. 456-485.

Nota: * En la fuente los datos de Girona y Tarragona no se dan por partidos judiciales, sino por pueblos y ciudades. En este cuadro se recogen los totales provinciales. 
Estos cuatro partidos judiciales concentraban el 59,7\% de los husos de hilar, casi todos en tecnología bergadana. Otra característica era el tamaño de los establecimientos. Cuando calculamos el número de husos por fábrica -Cuadro 1, columna terceraobtenemos las medias más bajas. En Vic y en Berga estamos en los 400 husos por fábrica -3,3 bergadanas de 120 husos-; en Manresa, donde se mezclan dos modelos, como veremos después, sale una media de unos 600 husos, y en Igualada es donde encontramos los establecimientos con más husos -746 y 6,2 bergadanas- aunque es una cifra inferior a la de los partidos judiciales con hilatura de mules.

La segunda geografía hiladora que se deduce de los Cuadros 1 y 2 es la hilatura de la continua, que se desarrolló casi únicamente en el partido judicial de Manresa -aunque, en realidad, en la ciudad y algunos pueblos como Cardona, Navarcles o Castellgalí-, y donde se concentraba el 78,2\% de las máquinas de este tipo, mezclándose con la hilatura de bergadanas en Sallent, Santpedor y otras poblaciones ${ }^{35}$. Las continuas y la maquinaria complementaria necesitaban motor hidráulico y su instalación llevó a un primitivo desarrollo de las fábricas de río. No es de extrañar, pues, que Manresa concentrase en el año 1841 el 43,8\% de los caballos de vapor hidráulicos instalados en Cataluña y dedicados a la industria textil. Lo que no podemos saber es el número de husos de continuas porque aparecen mezclados con los de bergadana del partido judicial, pero es posible que tuviesen menos que las bergadanas ${ }^{36}$.

La tercera geografía que se observa es la de la hilatura de la mule de madera y de pocos husos. Las mules se localizaban en el partido de Barcelona -el 62,6\% de las máquinas-, en Mataró-16,3\%-y en Arenys de Mar-2,8\%. Si miramos el peso de esta máquina sobre el total de máquinas de cada partido, los datos se confirman -el 84,9\% en Barcelona, el 89,2\% en Arenys y el 79,2\% en Mataró. Era el modelo de la costa frente a la bergadana en el interior. En el Cuadro 2 se muestra también la correspondencia de esta hilatura con un tipo de motor, en este caso las caballerías: el 55,8\% del total se encuentran en Barcelona, el 3\% en Arenys y el 16,7\% en Mataró. Solo Igualada utilizaba este tipo de motor en una cantidad importante-12,7\%-, aunque no tenía mules, tal vez porque la escasez de agua -o la gran cantidad de bergadanas que era preciso alimentarllevó a cardar algodón utilizando la tracción animal como fuerza motriz. Hay que señalar que eran fábricas más grandes que las formadas por bergadanas, que giraban alrededor de 900 husos de media -958 en Arenys, 905 en Barcelona y 857 en Mataró. Estas tres geografías las hemos representado en los Mapas 1 a 3.

\footnotetext{
${ }^{35}$ En realidad, mantener el criterio de partidos judiciales al que nos aboca la estadística de Madoz distorsiona la realidad del partido de Manresa. De hecho, la zona de continuas correspondería a Manresa ciudad y algunos pueblos próximos -Castellgalí, Navarcles, etc.-, ya que el resto del partido -Sallent, Santpedor, Balsareny, etc.- era una zona de bergadanas. Si pudiésemos desagregar los datos, el partido de Manresa habría que dividirlo claramente en dos áreas de hilatura distintas.

${ }^{36} \mathrm{Si}$ consideramos que cada bergadana tenía 120 husos, podemos saber el número de husos de bergadana que había en Manresa: 112.080. Quedaban entonces 25.907 husos de mule -en 74 máquinas- y de continua -226 de éstas. Si repartimos los husos, nos dan 86,4 husos por máquina no bergadana.
} 


\section{MAPA 1}

\section{La hilatura de la bergadana en Cataluña (1841)}

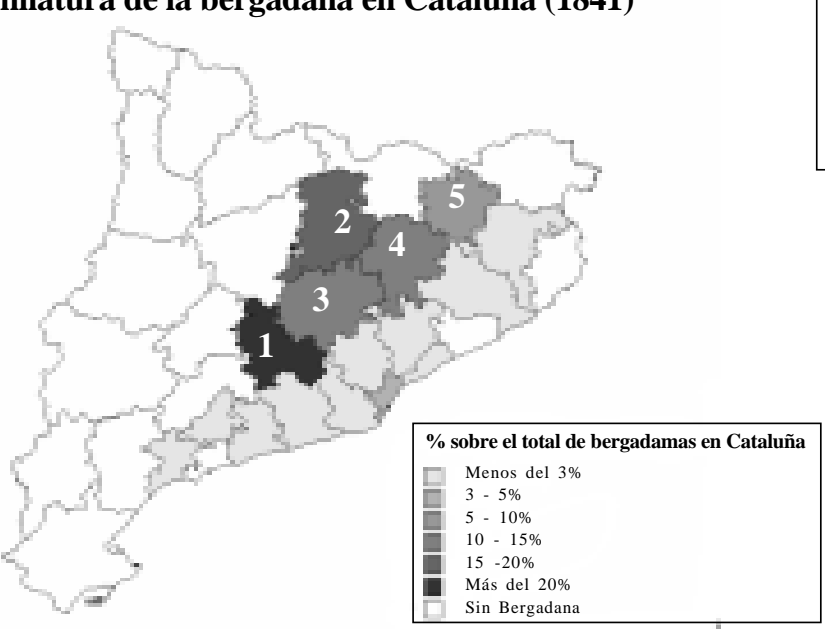

4. Vic

5. Olot

MAPA 2

La hilatura de la mule en Cataluña (1841)

1. Barcelona

thentary

2. Mataró

1

\% sobre el total de mule en Cataluña

$3-5 \%$
$5-10 \%$

$10-15 \%$

Más del $20 \%$

Sin mule

Fuente: Cuadro 1 y Madoz (1845-1850), Vol. III, 457 y ss. 
MAPA 3

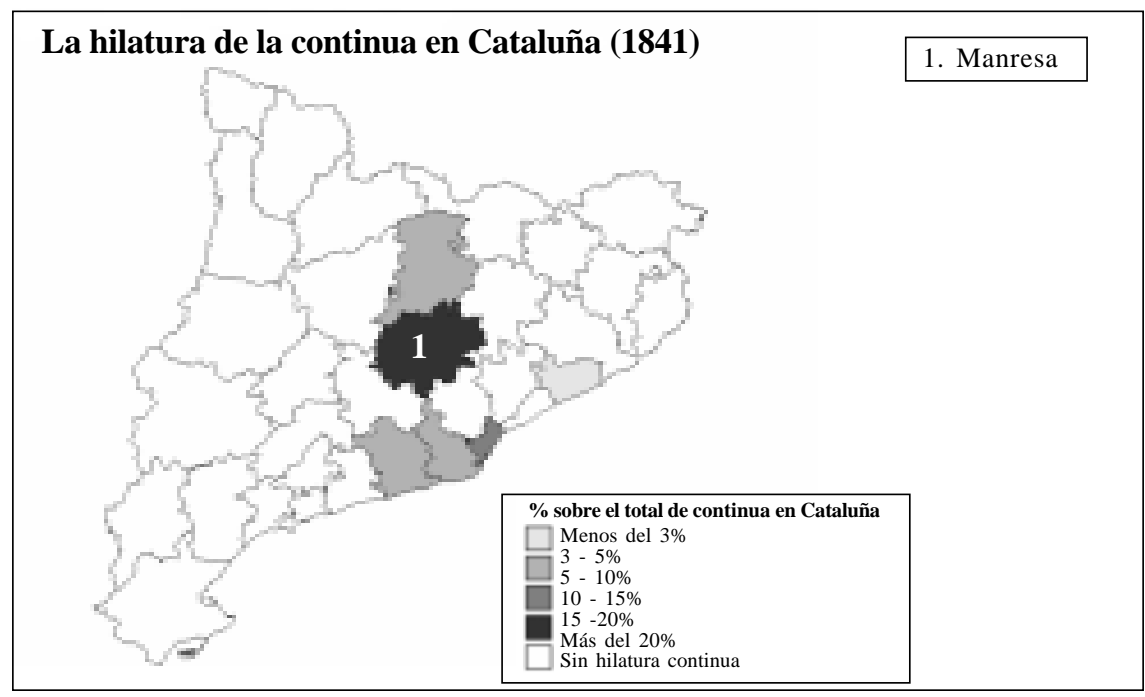

Fuente: Cuadro 1 y Madoz (1845-1850), Vol. III, 457 y ss.

¿Qué otras diferencias se observan entre las tres geografías a partir de los datos aportados por Madoz? En el Cuadro 3 hemos querido analizar el tipo de hilado que se producía en cada zona ${ }^{37}$. En este caso hemos simplificado el cuadro, es decir, sólo proporcionamos los datos de los partidos judiciales más destacados de cada área geográfica. Los resultados son muy claros: en el área de la bergadana se producen números bajos ${ }^{38}$, esto es, hilos más gruesos, ya que en todos los partidos los números del 10 al 20 suponen por encima del 90\% del hilado produ-

${ }^{37}$ Seguramente los interesantes datos estadísticos que aporta Madoz pierden calidad cuando entramos en datos cualitativos sobre número de hilo, producción o capitales. Pero aún así creemos que recogen la tendencia de cada zona.

${ }^{38}$ Aunque García Balañá (2001, pp. 201-206) insinúa que las jennies producían hilos más finos y las continuas hilos más irregulares y de menor calidad, todo hace pensar que sucedía lo contrario, si hacemos caso de los números de hilado que producían. El sistema catalán de numeración es un sistema inverso, es decir, cantidad de madejas de hilo por unidad de peso, lo que quiere decir que, si el hilo es más fino, el número será más alto. Vid. Ferrer Vidal (1874, pp. 68-71). Por otro lado, en la misma estadística que proporciona Pascual Madoz (1845-1850, p. 466), el hilo que tiene más precio es el número más alto. A pesar de esto, la importancia del trabajo manual en la bergadana hacía que la destreza individual de la hiladora permitiese producir hilos más regulares y más finos que otras hilaturas, de tal manera que la norma de hilos gruesos y tramas seguramente no era universal. 
cido, excepto en Vic, donde están un poco por debajo; en cambio en los partidos de mules, a pesar de que los hilados de números bajos son mayoritarios -entre el 50 y el $60 \%$ de la producción-, hilados un poco más finos con números altos -del 20 al 30- ocupan el 40\%; lo mismo ocurre en el partido de Manresa donde se combinan bergadanas y continuas, lo que induce a pensar que las continuas hilaban hilos más finos -números altos-, mientras la bergadana hilaba hilos más gruesos -números bajos.

El cuadro permite observar también las diferencias de productividad por huso en las distintas zonas. La estadística proporciona la producción de hilado en libras mensuales, de tal manera que, dividiendo la producción por el número de husos, podemos calcular aproximadamente la productividad por huso: en la zona de mules la producción está por encima de 2 libras por huso y mes, mientras en la zona de la bergadana estaba entre 0,43 libras/mes y una libra en el caso del partido de Igualada. En el área de continuas, la producción se situaba en 0,91 libras por uso y mes. Es decir, los husos de mule rendían más del doble que los de bergadana.

\section{CUADRO 3}

TIPOS DE HILADO PRODUCIDO EN DISTINTAS ÁREAS HILADORAS EN CATALUÑA EN 1841

\begin{tabular}{|c|c|c|c|c|c|c|c|c|}
\hline & \multirow{2}{*}{$\begin{array}{l}\text { Producción } \\
\text { total de hilo } \\
\text { (libras) }\end{array}$} & \multicolumn{2}{|l|}{$\begin{array}{l}\text { Números } \\
10 \text { al } 20\end{array}$} & \multicolumn{2}{|c|}{$\begin{array}{l}\text { Números } \\
20 \text { al } 30\end{array}$} & \multicolumn{2}{|c|}{$\begin{array}{l}\text { Números } \\
30 \text { al } 45\end{array}$} & \multirow{2}{*}{$\begin{array}{c}\text { Produc- } \\
\text { ción por } \\
\text { huso } \\
\text { (libras) }\end{array}$} \\
\hline & & $\begin{array}{c}\% \\
\text { partido }\end{array}$ & $\begin{array}{c}\% \\
\text { tipo }\end{array}$ & $\begin{array}{c}\% \\
\text { partido }\end{array}$ & $\begin{array}{c}\% \\
\text { tipo }\end{array}$ & $\begin{array}{c}\% \\
\text { partido }\end{array}$ & $\begin{array}{c}\% \\
\text { tipo* }\end{array}$ & \\
\hline \multicolumn{9}{|c|}{ Hilatura de mule: } \\
\hline Arenys de Mar & 17.600 & 19,9 & 0,3 & 52,8 & 2,4 & 22,7 & 4,9 & 2,04 \\
\hline Barcelona & 635.144 & 61,2 & 37,4 & 30,2 & 49,2 & 6,5 & 50,0 & 2,56 \\
\hline Mataró & 138.740 & 53,0 & 7,1 & 37,9 & 13,5 & 7,8 & 13,2 & 2,45 \\
\hline \multicolumn{9}{|c|}{ Hilatura de bergadana: } \\
\hline Berga & 78.510 & 89,2 & 6,7 & 10,8 & 2,2 & - & - & 0,43 \\
\hline Igualada & 309.540 & 99,7 & 29,7 & 0,3 & 0,3 & - & - & 1,00 \\
\hline Vic & 53.410 & 75,8 & 3,9 & 20,1 & 2,8 & 4,1 & 2,7 & 0,82 \\
\hline Olot & 14.260 & 89,4 & 1,2 & 10,6 & 0,4 & - & - & 0,48 \\
\hline \multicolumn{9}{|c|}{ Hilatura de continua y bergadana: } \\
\hline Manresa & 125.010 & 56,1 & 6,7 & 40,2 & 12,9 & 3,7 & 5,7 & 0,91 \\
\hline
\end{tabular}

Fuente: Madoz (1845-1850), Vol. III, pp. 456-485.

Nota: * Los totales no suman 100 porque en el cuadro sólo están los partidos judiciales seleccionados. 
Esta geografía de la hilatura del algodón se complementaba con otra geografía del tejido o, dicho de otra manera, no se podía separar la hilatura, fuese del tipo que fuese, del tejido manual. La historiografía ha tendido a dejar de lado el tisaje manual para concentrarse en el mecánico, de la misma manera que ha dado prioridad al estudio de la máquina de vapor y se ha olvidado de las diferentes hilaturas que durante un tiempo fueron la base productiva y de crecimiento de determinadas zonas. Es, pues, necesario colocar al tisaje manual en el lugar que le corresponde, y el punto de partida es la utilización de las estadísticas sobre Cataluña del año 1841. Uno de los problemas de fondo que enmascaran la realidad es que hilatura y tisaje son contemplados separadamente en la fuente que trabajamos y, en cambio, sabemos que muchas fábricas que hilaban con bergadanas tejían al mismo tiempo. Hilatura y tisaje, por lo menos en la Cataluña de las bergadanas, eran dos caras de la misma moneda.

\section{CUADRO 4}

\section{ESTABLECIMIENTOS DE TEJIDOS Y NÚMERO DE TELARES EN CATALUÑA, POR PARTIDOS JUDICIALES, EN 1841}

\begin{tabular}{|c|c|c|c|c|c|c|c|c|}
\hline $\begin{array}{l}\text { Partido } \\
\text { judicial }\end{array}$ & $\begin{array}{c}\text { Estable- } \\
\text { cimientos }\end{array}$ & $\begin{array}{c}\text { Telares } \\
\text { sencillos }\end{array}$ & $\begin{array}{c}\text { Telares } \\
\text { compuestos }\end{array}$ & $\begin{array}{c}\text { Telares } \\
\text { Jaquard }\end{array}$ & $\begin{array}{c}\text { Telares } \\
\text { mecánicos }\end{array}$ & $\begin{array}{c}\text { Total } \\
\text { telares }\end{array}$ & $\begin{array}{c}\text { Telares/ } \\
\text { estable- } \\
\text { cimiento }\end{array}$ & $\begin{array}{l}\text { \% total } \\
\text { telares }\end{array}$ \\
\hline \multicolumn{9}{|c|}{ Provincia de Barcelona: } \\
\hline Arenys & 33 & 544 & 2 & - & - & 546 & 16,5 & 2,1 \\
\hline Barcelona & 460 & 6.098 & 2.913 & 945 & 52 & 10.008 & 21,8 & 39,1 \\
\hline Berga & 406 & 2.037 & - & - & - & 2.037 & 5,0 & 7,9 \\
\hline Granollers & 19 & 118 & - & - & - & 118 & 6,2 & 0,5 \\
\hline Igualada & 316 & 1.663 & 108 & - & - & 1.771 & 5,6 & 6,9 \\
\hline Manresa & 158 & 846 & 76 & - & 72 & 994 & 6,3 & 3,9 \\
\hline Mataró & 157 & 3.110 & 23 & - & - & 3.133 & 20,0 & 12,2 \\
\hline Sant Feliu & 14 & 155 & 11 & - & 20 & 186 & 13,3 & 0,7 \\
\hline Terrassa & 47 & 868 & - & - & - & 868 & 18,5 & 3,4 \\
\hline Vic & 181 & 1.120 & 190 & - & - & 1.310 & 7,2 & 5,1 \\
\hline Vilafranca & 7 & 33 & 11 & - & 60 & 104 & 14,9 & 0,4 \\
\hline \multicolumn{9}{|c|}{ Provincia de Girona: } \\
\hline Olot & 429 & 1.158 & 35 & - & - & 1.193 & 2,8 & $4, \overline{7}$ \\
\hline Sta. Coloma & 49 & 134 & - & - & - & 134 & 2,7 & 0,5 \\
\hline Otros & 59 & 477 & 43 & - & 6 & 526 & 8,9 & 2,1 \\
\hline \multicolumn{9}{|c|}{ Provincia de Tarragona: } \\
\hline Reus & 79 & 241 & 1.612 & 1 & - & 1.854 & 23,5 & 7,2 \\
\hline Valls & 90 & 30 & 763 & - & - & 793 & 8,8 & 3,1 \\
\hline Otros & 10 & 27 & 18 & - & - & 45 & 4,5 & 0,2 \\
\hline Totales & 2.514 & 18.659 & 5.805 & 946 & 210 & 25.620 & 10,2 & 100,0 \\
\hline
\end{tabular}

Fuente: Madoz (1845-1850), Vol. III, pp. 456-485. 
Hilatura y tisaje se complementaban, ya que no había una geografía diferenciada y las mismas comarcas que hilaban concentraban los telares, aunque el peso del tejido no coincida exactamente con el de la hilatura. Por un lado, allí donde había mules existía más concentración de telares. Así Barcelona concentraba el 39,1\% de los telares y Mataró el 12,2\%. Más lejos quedaban Berga -8\%-, Reus -7,2\%-, Igualada -6,9\%- y Vic -5,1\%-, una situación muy diferente a la que se producía en la hilatura, en la que los husos estaban más repartidos entre la zona de la bergadana y la de la mule ${ }^{39}$. Hay que pensar también que la estadística publicada por Madoz recogía solamente los establecimientos que, como tales, se consideraban de tejidos de algodón, pero no creemos que estén incorporados telares que se encontraban en los hogares campesinos y que trabajaban para un determinado fabricante, seguramente más abundantes en la Cataluña interior que en Barcelona ${ }^{40}$. En aquel momento, los telares mecánicos no eran significativos, ya que estaban empezando a introducirse en las fábricas de río antiguas y en las nuevas fábricas que utilizaban el vapor como energía ${ }^{41}$.

El Cuadro 5 también permite distinguir el tipo de telar. El 72,8\% eran telares sencillos dedicados mayoritariamente a la producción de tejidos de empesa de algodón, el 22,7\% compuestos y el 4,9\% jacquards. Cuando analizamos dónde estaban ubicados aquellos telares que no eran sencillos, observamos que el 50,2\% de los compuestos estaban en Barcelona, el 27,7\% en Reus y el 13,1\% en Valls, es decir, allí donde había una especialización en tejidos más sofisticados de novedad y de mezcla que la simple empesa de algodón. Todos los telares jacquard estaban ubicados en Barcelona.

${ }^{39}$ Manresa tenía un peso poco relevante en el campo del tejido según estos datos, pero hay que matizarlo, ya que en la ciudad había una activa industria de la seda que seguramente evolucionaba hacia tejidos de mezcla, y una cintería que también utilizaba el algodón. El mismo Pascual Madoz (1845-1850, III, p. 479) escribía sobre los telares de seda de Manresa: «En 1841 había ya en Barcelona, según los datos del Sr. Sayró, sobre 1300 telares de seda, cuyas dos terceras partes son a la jaquard; de 600 a 700 inclusos los de cintas en Manresa, más de 300 en Reus y muy pocos en Mataró». En cambio, en Reus, los tejidos de mezcla de algodón y seda deberían ser más importantes y están incorporados a las estadísticas que aporta Madoz. Es lo que explica que Reus tuviese una importante concentración de telares.

40 «A más de interesar en la espresada sociedad hacía tejer piezas en Santpedor, Navarcles, Artés y me parece alguna otra, las que se mandaba a la casa de Barcelona la que regentaba su hermano Lluis Pons Enrich con el que formaba sociedad y a más se dedicaban a la compraventa de seda en rama y a la venta de pañuelos y cintas de seda y algodón para lo cual tenían empleadas en Manresa más de trescientos trabajadores entre hombres y mujeres que trabajaban en sus respectivas casas y cuyos telares y demás máquinas y aparatos de trabajo eran propios de los trabajadores». Biografía de Josep Pons Enrich, escrita por su hijo Lluis Pons Enrich, AHCM, Familia Pons. Vid. Ferrer i Alòs (1985) y Serra y Vilades (1987).

${ }^{41}$ Madoz (1845-1850) apunta la fecha de 1828 como la de introducción del telar mecánico en Cataluña, de la mano de Joan Vilaregut. En Sallent tuvieron que empezar a funcionar en el año 1830, ya que es la fecha en que este fabricante arrendó la fábrica de Cal Torres, como veremos más adelante. 
Otro hecho significativo es el número de telares por establecimiento -Cuadro 5, columna 7. Hay una división clara entre la zona de la bergadana en la cual los establecimientos se mueven en torno a una media de 5 a 8 telares, por tanto muy pequeños, y los de la zona mule -Barcelona y Maresme-, con una media que se sitúa en los 20 telares, es decir, mucho más grandes. El mismo fenómeno se produce en Reus, donde se llega a los 23 telares y apenas hay hilatura.

Los datos de Madoz distinguen en el ámbito estadístico entre establecimientos de hilados y establecimientos de tejidos, aunque en la práctica pudieran ser los mismos establecimientos. Si observamos en el Cuadro 5 los establecimientos de hilados, vemos que donde hay más es en Berga e Igualada -47,7\% del total-, seguidos a mucha distancia de Barcelona -15,5\%-y Manresa -12,9\%-, aunque esta distribución no coincida con el número de husos -Berga e Igualada concentran el 42,3\% de los husos y Barcelona llega hasta el 21,4\% porque son establecimientos con más husos- ni con la cantidad de hilado elaborado. Si hacemos caso de los datos $-\mathrm{y}$ pensamos que seguramente la calidad de los mismos empeora cuando entramos en el campo de la producción y de los capitales-, Barcelona producía el 39,8\% del algodón hilado frente al 19,5\% de Igualada y un increíble, por bajo, 4,9\% de Berga, las zonas donde había más husos de bergadana. La productividad de las mules de madera movidas por caballería era superior a la de las máquinas manuales, lo que explica los datos, pero debemos tener en cuenta que estamos en la etapa final de un modelo y en la del nacimiento de otro que ya empieza a aparecer en las estadísticas -introducción del vapor y mules de hierro más productivas- y que afecta especialmente a Barcelona, lo que puede distorsionar algunos cálculos.

La geografía de las empresas de tejidos cambia según consideremos el número de establecimientos o el número de telares En Berga, Igualada y Vic se concentraban el 36,6\% de los establecimientos, y si añadimos Olot, que también era un área de bergadanas, llegamos al 53,7\% del total de fábricas de tejidos ${ }^{42}$. Ahora bien, si consideramos el número de telares, los números cambian radicalmente. Berga, Igualada, Vic y Olot concentraban solo el 27,2\% de los telares, mientras que los partidos judiciales con más telares, y por tanto las grandes áreas de tisaje, eran Barcelona -39,1\%-, Mataró -12,2\%- y Reus -7,2\%-, aunque estos porcentajes varían un poco si consideramos las piezas tejidas: el área de la mule tejía el 47,7\% de las piezas, la de la bergadana el 25,6\%, y en Reus y Valls el 9,3\% del total. Esto quiere decir que la hilatura de la bergadana se complementaba con pequeñas fábricas de tejidos de algodón en crudo, pero donde se concentraba el tejido era en Barcelona, Mataró y Reus.

${ }^{42}$ Los establecimientos de Manresa representan solo el 6,3\% del total. Debe considerarse que en Manresa continuaban siendo muy importantes los tejidos de seda y la cintería, los cuales acaparaban una parte importante de la producción textil. Estos telares no están incorporados a esta estadística. 


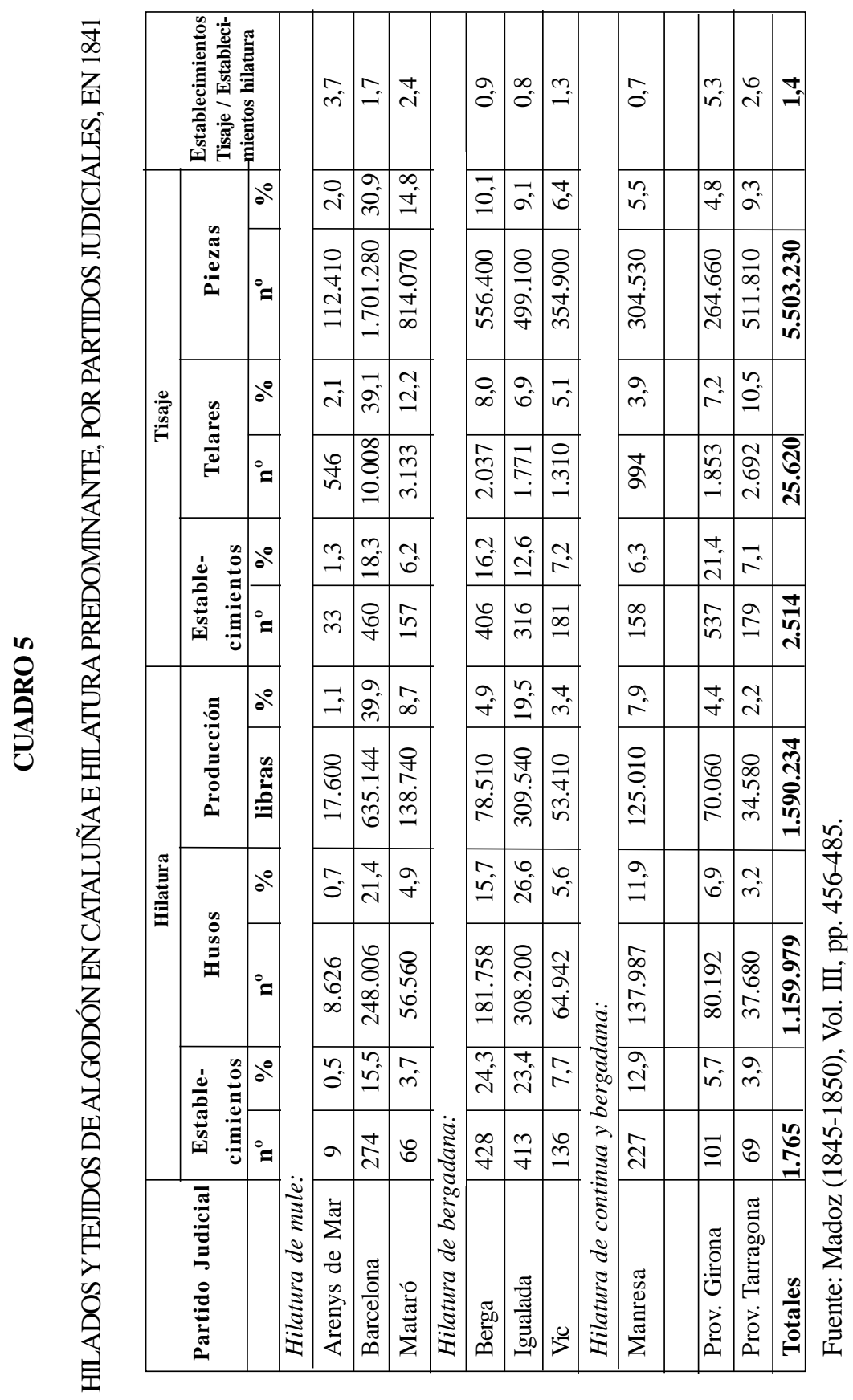


La última columna del Cuadro 5 compara el número de establecimientos de tejidos y de hilados y da una relación de 1,4, es decir, que había más establecimientos de tejidos. Muy por encima de esta cifra encontramos los partidos de Arenys de Mar, Barcelona, Mataró, Olot, Reus y Valls, lo que da a entender que hilatura y tisaje estaban claramente separados o que corrían a cargo de empresas diferentes. De hecho, son los partidos judiciales de utilización de la mule, excepto en los casos de Olot y Reus, aquellos en los que solo existe el tisaje. En cambio, en la zona de la bergadana la relación está próxima a uno, aunque ligeramente por debajo, lo que indicaría un ligero predominio de los establecimientos hiladores: Berga -0,95-, Igualada -0,8-, Manresa -0,7- y Vic -1,33.

¿Hilatura y tisaje formaban parte del mismo establecimiento ${ }^{43}$ ? Las estadísticas de Madoz los tratan de forma separada, pero puede que sea a efectos puramente de cálculo. En el mismo diccionario se catalogan nominativamente los establecimientos de hilados y tejidos de Berga, una zona típica de bergadana. Para conocer si eran los mismos establecimientos o eran diferentes hemos buscado la coincidencia en el nombre de la empresa. El resultado se resume en el Cuadro $6^{44}$.

CUADRO 6

ESTABLECIMIENTOS Y MAQUINARIA TEXTIL EN BERGA, 1841

\begin{tabular}{|c|c|c|}
\hline & \multicolumn{2}{|c|}{ Establecimientos } \\
\hline & número & $\%$ \\
\hline Hilados y tejidos & 156 & 91,2 \\
\hline Sólo hilados & 6 & 3,5 \\
\hline Sólo tejidos & 9 & 5,3 \\
\hline \multirow[t]{3}{*}{ Totales } & 171 & 100,0 \\
\hline & \multicolumn{2}{|c|}{ Maquinaria } \\
\hline & número de máquinas & máquinas/establecimiento \\
\hline Bergadanas & 710 & 4,38 \\
\hline Telares & 900 & 5,50 \\
\hline
\end{tabular}

Fuente: Madoz (1845-1850), Vol. III, pp. 456-485.

${ }^{43}$ Una crítica a la fuente desde el punto de vista del tamaño de las empresas puede encontrarse en Maluquer de Motes (1976, p. 140). Este autor también señala que la separación entre establecimientos de hilados y de tejidos es ficticia, ya que en muchos lugares eran el mismo establecimiento.

${ }^{44}$ Seguramente para ahorrar espacio, proporciona los datos de forma poco habitual: las fábricas se agrupan en grupos de tres, da el nombre de cada una de ellas y proporciona datos de las máquinas, obreros y capitales agrupados. Creemos que es una lista individual, aunque se podría pensar que se trataba de sociedades, pero ni se indica ni podemos pensar que todas las fábricas eran sociedades. Véase Madoz (1845-1850, Berga, pp. 252-257). 
La fábrica típica de Berga según estos datos sería un establecimiento que se dedicaba a hilar y tejer, de tamaño modesto, con 4,38 bergadanas $-525,6$ husos- $\mathrm{y}$ 5,5 telares. La fábrica más grande de la relación de Madoz no se alejaba mucho de este prototipo: parece que no había ninguna con más de ocho bergadanas -960 husos- y la mayor tenia 28 telares. Es muy probable que toda la zona de bergadanas tuviese más o menos la misma estructura.

Las características de las tres áreas hiladoras se pueden profundizar a partir de los datos que Madoz aporta sobre la mano de obra por géneros y distinguiendo entre niños y adultos que se utilizaba en cada zona, datos que se resumen en el Cuadro $7^{45}$.

En las zonas de hilatura de bergadanas prácticamente no se utilizaba mano de obra masculina en la hilatura: Berga 1,3\%, Igualada 3,2\%, Manresa 5\%, Vic 3,1\%, Olot 1,7\% y Santa Coloma 0,9\%. Si bien la mano de obra femenina era mayoritaria -entre el 48,9\% de Berga y el 63,6\% de Santa Coloma-, la mano de obra infantil significaba más de un tercio del personal ocupado-37-38\%, con la excepción de Berga, donde llegaba al 49,8\%.

En el caso de Manresa, donde se mezclaban continuas y bergadanas, la única distinción era que el porcentaje de los varones ascendía al 5\%, lo que hace pensar que las continuas utilizaban un poco más de mano de obra masculina que las bergadanas. En cambio, las zonas de mules se caracterizaban por una presencia más elevada de varones -9\% en Barcelona, 11\% en Mataró-, menos niños -entre el 20 y el 21\%- y más mujeres -entre el 68 y 69,5\%. Las características de las máquinas hacían que las mules movidas por caballerías fuesen máquinas, por así decirlo, un poco más masculinas.

El tisaje manual era una ocupación masculina. El porcentaje de hombres se situaba entre el 55 y $65 \%$ y encontramos una correlación perfecta entre varones y número de telares. Las mujeres y los niños hacían trabajos de preparación y, también en este caso, los niños eran menos en número en Barcelona/ Mataró -8-8,5\%que en las zonas de bergadanas $-12-14 \%$. De hecho esta sería la única diferencia en el tisaje entre las distintas zonas hiladoras.

La coexistencia de diversas zonas hiladoras con tecnologías totalmente distintas puede explicarse por las diferencias salariales de las citadas zonas. Madoz proporciona lo que se pagaba en salarios en cada partido judicial por sexos y, aunque los datos pueden tener algún problema de fiabilidad como el mismo Madoz reconocía, se observan unas tendencias muy claras en cada zona. En el Cuadro 8 hemos recogido las diferencias salariales por sexos y por partidos judiciales en la hilatura y el tisaje.

${ }^{45}$ Para evitar distorsiones hemos dejado fuera aquellos partidos judiciales en que el número de establecimientos era inferior a 20. 


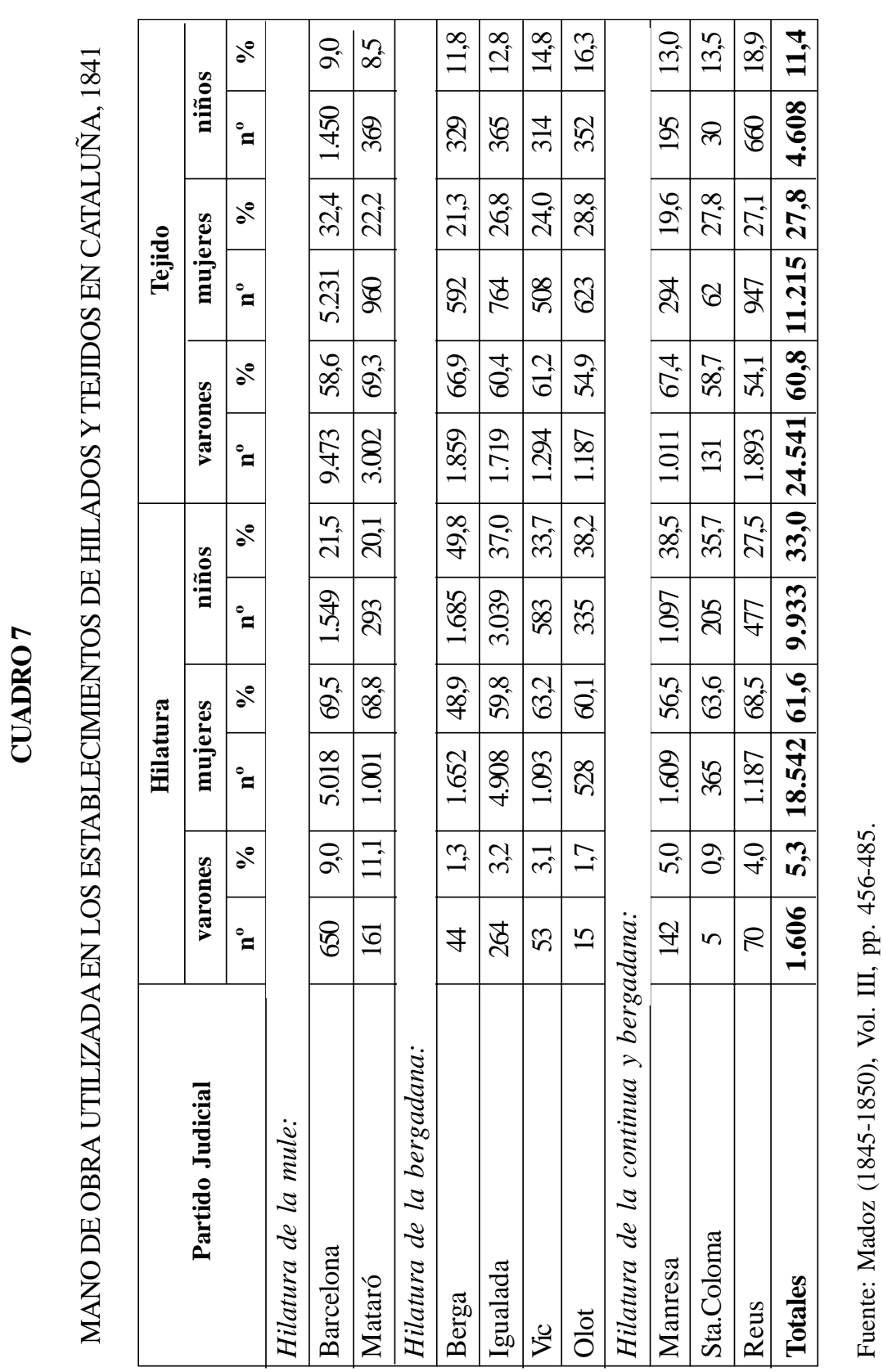




\section{CUADRO 8}

\section{SALARIOS MENSUALES EN LA HILATURA Y EL TEJIDO EN CATALUÑA} SEGÚN TIPO DE HILATURA, EN 1841

(Reales de vellón)

\begin{tabular}{|c|c|c|c|c|c|c|}
\hline & \multicolumn{3}{|c|}{ Salario mensual hilatura } & \multicolumn{3}{|c|}{ Salario mensual tejido } \\
\hline & varón & mujer & niño & varón & mujer & niño \\
\hline \multicolumn{7}{|c|}{ Hilatura de mule: } \\
\hline Arenys & 286,1 & 116,4 & 51,9 & 178,3 & 94,4 & 36,2 \\
\hline Barcelona & 272,8 & 172,5 & 50,0 & 219,3 & 93,6 & 56,1 \\
\hline Mataró & 298,6 & 146,5 & 59,0 & 191,8 & 94,9 & 55,4 \\
\hline \multicolumn{7}{|c|}{ Hilatura de la bergadana: } \\
\hline Berga & 217,3 & 59,2 & 36,6 & 131,5 & 48,9 & 32,7 \\
\hline Igualada & 146,1 & 76,8 & 41,9 & 166,7 & 73,2 & 55,2 \\
\hline Vic & 374,9 & 60,1 & 33,6 & 167,4 & 45,0 & 33,9 \\
\hline Olot & 164,7 & 59,8 & 33,4 & 144,1 & 47,2 & 34,0 \\
\hline \multicolumn{7}{|c|}{ Hilatura de la continua y la bergadana: } \\
\hline Manresa & 290,8 & 70,2 & 38,9 & 156,7 & 54,6 & 38,6 \\
\hline Reus & 203,3 & 80,6 & 49,3 & 207,0 & 70,3 & 38,4 \\
\hline
\end{tabular}

Fuente: Madoz (1845-1850), Vol. III, pp. 456-485.

Aunque observamos algunas incongruencias en las diferentes zonas -el alto precio de los salarios de las hiladoras de Vic o el de las mujeres tejedoras en Igualada, derivado seguramente de distorsiones en las fuentes-, los datos son bastante homogéneos. En la zona de hilatura con mules los salarios eran mucho más altos: un hombre cobraba entre 272 y 298 reales, una mujer entre 116 y 146 y un niño entre 50 y 59 reales, mientras en la zona de bergadanas los hombres cobraban entre 146 y 164, las mujeres entre 59,2 y 76,8 y los niños entre 33,4 y 33,6. Algo parecido ocurría en el tisaje. Calculando la media entre los precios de los diferentes partidos, se podría decir que los hombres de la zona de mule cobraban un $62 \%$ más que aquellos que trabajaban en la zona de bergadanas, las mujeres un $70 \%$ más y los niños, un $47 \%$ más. En los tejidos, los hombres cobraban un 28,9\% más, las mujeres un 100\% más y los niños, un 26,5\%. En Manresa todos los salarios se sitúan en una posición intermedia, y en Reus los salarios de los tejedores se acercan más a los salarios de Barcelona, seguramente debido al alto grado de especialización. Había, por tanto, diferencias salariales importantes de una zona a otra. 
Los datos de Pascual Madoz han puesto en evidencia -en un momento que ya empezaba a ser de cambio- la existencia durante bastante tiempo de tres geografías que se corresponden con una determinada tecnología hiladora y con características organizativas, productivas y de costes específicas. A continuación vamos a complementar éste análisis con algunos datos microhistóricos sobre Sallent -un pequeño municipio con predominio de la bergadana y cardado mecánico del algodón- y sobre Manresa, donde se desarrolló una activa industria basada en las continuas.

\section{EL MODELO DE LA BERGANADA DE SALLENT EN EL INTERIOR DE CATA- LUÑA}

Sallent está situado en el curso medio del río Llobregat. La etimología nos dice que significa «salto de agua» y visitando la villa se descubre que el río tiene un pronunciado desnivel que hacía relativamente fácil aprovechar sus aguas obteniendo un salto sin apenas construir canal. Esto es lo que se había hecho a lo largo de los siglos, ya que aparecen noticias de molinos harineros, bataneros y polvoreros, y de canales para poder regar las tierras adyacentes al río. En este contexto era relativamente fácil reconvertir las infraestructuras industriales tradicionales para dedicarlas a actividades algodoneras ${ }^{46}$.

A mediados de la década de los noventa del siglo XVIII el avance algodonero se produjo por ósmosis, a partir del conocimiento de lo que estaba pasando en Berga, ciudad situada unos kilómetros más al norte. La aparición de personas que se calificaban como fabricantes de algodón, simultaneando con otros oficios, permite seguir el nacimiento de esta actividad. La palabra fábrica se refería a artilugio o máquina y, por lo tanto, fabricantes eran aquellos que usaban «fábricas» para el hilado del algodón ${ }^{47}$, aunque más tarde se utilizará el término para referirse al edificio. La referencia más antigua a un fabricante de algodón en Sallent son los capítulos matrimoniales firmados el 7 de junio de 1795 entre Vicens Vidal «paraire i fabricant de cotó» y Mónica Montanyàa ${ }^{48}$. La dualidad de actividades aparece como algo normal. Las noticias sobre fabricantes escasean en los últimos años del siglo y es a partir de 1800 cuando se multiplican y generalizan. En los protocolos notariales se encuentran documentos muy interesantes sobre esta primera época.

\footnotetext{
${ }^{46}$ Véase Benet Clará (1988 y 1989).

${ }^{47}$ Jaume Comas de Santpedor aparece como fabricante y se nos dice que «per a pagar lo import de una fábrica que dit Jaume fa construir». No se refiere a un edificio, sino a la máquina de hilar. (AHCM, Notario C. Mas 1796, fol. 53, 31-I).

${ }^{48}$ AHCM, Notario Ferrusola 1795, 7-VI.
} 
En el año 1796 Llorenç Claret se declaraba tejedor de algodón -unos años antes lo era de lino- y formaba una compañía muy especial con Francisco Enrich, francés de París y de formación maquinista ${ }^{49}$. Este prometía construir en tres meses una máquina de cardar y cuatro máquinas de hilar algodón que hilarían doce libras al día mediante el movimiento de mulos. Recibiría un salario de 2,5 pts., los gastos de manutención y todo lo que necesitase para la construcción de las máquinas. La compañía duraría cuatro años, y en este tiempo Enrich no podría construir ninguna otra máquina ni Claret podría «comunicarlas» a nadie. Al cabo de tres meses, Enrich no había cumplido y se prorrogaba el plazo tres meses más ${ }^{50}$.

¿Qué hacía un francés de París en Sallent? La transmisión de los secretos de las máquinas a través de personas de otros países parece haber sido una fórmula habitual. Hemos visto más arriba como en Cardona eran ingleses de Manchester los que las perfeccionaban. Las máquinas de hilar simples parecen extenderse a toda velocidad a finales de siglo y, a pesar de las prevenciones de retener la información y los secretos técnicos, los carpinteros y herreros locales las copiaron y multiplicaron. Eran gente, además, que ya estaba acostumbrada a fabricar y reparar artilugios de todo tipo ${ }^{51}$.

Las noticias sobre el tema escasean en los protocolos. Hay que esperar al año 1802 para encontrar la formación de otra modesta compañía, y no sabemos hasta qué punto era la forma normal de iniciar la actividad algodonera. La firmaban Agustí Escayola, bracero (sic) y Miquel Santcliment, fabricante de algodón ${ }^{52}$. El primero aportaba 300 libras de capital, una cantidad muy modesta, y el segundo dos máquinas de hilar y lo que hacía falta para que la fábrica funcionase. Santcliment se cuidaba de la fábrica y por ello recibía una cantidad de dinero de la cual tenía que pagar también a las hilanderas. Los beneficios se repartían a partes iguales una vez devuelto el capital. Un modesto socio capitalista invertía en algodón y busca-

${ }^{49}$ AHCM, Notario Camps 1796, 22-IX, fol. 285.

${ }^{50}$ AHCM, Not. Camps 1797, fol. 114, 18-III-1797.

${ }^{51}$ Llorenç Claret y Casas pertenecía a este tipo de familias que obtenían sus recursos de todas las posibilidades que les ofrecía la comunidad: tenía viñas (AHCM, Not. Ferrusola, 1783, fol. 191), su padre se declaraba paraire (AHCM, Not. Ferrusola, test. 1764-1779, fol. 302), su hermano y él eran tejedores de lino hasta finales de siglo en que aparecen como tejedores de algodón y más tarde como fabricantes, y tenemos noticias de que se dedicaban al arrendamiento de los cereales que producían algunos campesinos. En el testamento de su padre aparece como el segundo hermano varón, aunque parece que se convirtió en heredero por muerte de su hermano. Sus hermanas contrajeron matrimonio con un tendero, un botero y un sedero de Manresa y con un paraire de Sallent, y tenía un hermano dedicado al comercio en Cádiz. Una red, pues, que muestra las conexiones con Manresa donde había una dinámica muy activa. Pasaron por algunas dificultades en los primeros años del siglo XIX, quizá para hacer frente a la inversión necesaria para poner en marcha la fábrica Vella como después veremos (AHCM, Not. Camps, 1800, fol. 231; 1805, fol. 304 y 1812 fol. 3). En el año 1796 se metió en el algodón como una actividad más.

${ }^{52}$ AHCM, Not. Camps, 1802, fol. 10. 
ba un técnico que conociera el nuevo oficio, el cual aportaba trabajo y conocimientos a cambio de un salario fijo y una participación en los beneficios. Este parece ser el modelo de estas primeras fábricas.

¿Era el capitalista un bracero? La asignación de profesiones es un problema cuando las actividades son múltiples, y no es extraño que en el año 1805 se le denomine comerciante. Este año se firma una nueva compañía entre los dos socios con unas cláusulas bastante diferentes por un período de tres años. El capital de 706 libras -continúa siendo modesto- lo proporcionan a partes iguales los dos socios que, al mismo tiempo, aportan máquinas -tres de hilar Agustí y tres de hilar y dos telares Miquel-y acuerdan ir a pérdidas y ganancias. Miquel era quien se haría cargo de la fábrica a cambio de 11 pts. a la semana y quien buscaría a los operarios. Queda bien señalado que las piezas se llevaban a Barcelona, que era el mercado único de los tejidos de algodón, y se preveía que, si ocurrían robos en los viajes a Barcelona -indica que el peligro existía-, se pagaría de los fondos de la compañía ${ }^{53}$.

Otra de las compañías que repite este modelo es la que se firmó entre Joan Bosch, pastelero de Sallent y Anton Casajoana, fabricante de algodón. El primero invertía 283 libras y dos máquinas de hilar, dos tornos y otros pequeños artefactos. Anton ponía dos máquinas, dos tornos y dos telares y se cuidaría de la fábrica, del personal y de ir a Barcelona a comprar algodón y vender las piezas, y a cambio recibiría un salario de 11 pts. a la semana. Las ganancias o pérdidas se repartirían a medias ${ }^{54}$. La sociedad se disolvió en el año $1814^{55}$.

Nos podemos hacer una idea de cómo eran estas primeras fábricas: tenían entre dos y seis máquinas de hilar -ninguna mayor de 80 husos-, entre dos y cuatro telares, tornos de hilar para preparar la mecha y sólo en dos casos se citan las

${ }^{53}$ AHCM, Not. Camps 1805, fol. 147, 22-IV-1805. La liquidación de la compañía se realizó en el año 1808 (AHCM, Not. Camps, 1808, fol. 145). En los protocolos notariales se encuentra también la formación de una compañía que no llegó a firmarse pero que tiene el mismo planteamiento. Agustí Escayola, comerciante, ponía 300 libras, cinco máquinas de hilar, cuatro telares, una máquina de cardar y otros utensilios, mientras que Francisco Traveria, fabricante de algodón de l’Estany, ponía una máquina. Francisco haría funcionar la fábrica a cambio de 12 pts. a la semana y recibiría media peseta por la máquina; también su mujer recibiría un salario. El algodón se compraba en Barcelona y las piezas también se vendían allí, y las ganancias resultantes serían 2/3 partes para Escayola y la otra para Traveria. El control económico de la fábrica lo tendría Escayola (AHCM, Not. Camps 1804, fols. 249-250).

${ }^{54}$ AHCM, Not. Camps 1804, fol. 112, 13-IV-1804.

${ }_{55}$ AHCM, Not. Camps 1814, 25-IV-1814. Unos días después Josep Pujol, fabricante de algodón de Sallent reconocía querer pagar a Anton Casajoana, comerciante (sic) 90 libras que eran el resultado de la venta de dos máquinas de hilar de 60 husos y tres telares. Es posible que fueran las máquinas que había utilizado mientras hizo funcionar la compañía y que ahora servirían a otro para empezar (AHCM, Not. Camps 1814, fol. 58, 1-V). Anton aspiraba a más -a participar en una de las fábricas de río-, pero vemos cómo otro con unos orígenes humildes toma el relevo. 
máquinas de cardar. Se componían de dos socios, uno que proporcionaba un modesto capital y alguna máquina y otro que aportaba máquinas y cuidaba del funcionamiento, de la compra de algodón y de la venta de las piezas en Barcelona, así como de la selección del personal, todo ello a cambio de un salario fijo y una participación en los beneficios de la actividad. El miembro de la compañía que aportaba capital participaba en múltiples negocios dentro de la comunidad local y la inversión en el algodón era una entre tantas, mientras que el socio fabricante se metía de lleno en la nueva actividad: a algunos de ellos los encontraremos en las fábricas de río dedicadas al cardado del algodón.

A partir del año 1805 no hay referencias sobre la creación de sociedades y formas de colaboración parecidas y, sin embargo, los fabricantes de algodón -así se denominan en estos primeros años del siglo- se multiplican. Convertirse en algodonero debía tener perspectivas, ya que los protocolos notariales recogen ventas a carta de gracia ${ }^{56}$ de viñas y tierras para comprar lo que hace falta para montar una fábrica de algodón. Isidre Vallribera, trabajador -una categoría profesional muy imprecisa- vendía a carta de gracia una viña de 2 cuarteras por 150 libras «per una fabrica de cotó que de proxim espera plantar en la casa que posseheix situada en la present vila y carrer dit del Cos» ${ }^{57}$. En el año 1807 constaba como tejedor de algodón ${ }^{58}$. No es el único caso. Ignasi Solá y Ponsgrau, fabricante de algodón, vendía una viña por 600 libras para pagar algunas deudas y legados testamentarios pero, sobre todo, «per la fábrica que ha construit per collocar los instruments de son ofici de cotoner y satisfer lo import de las maquinas que ha plantat en dita fabrica y emplear lo restant preu per comprar cotó pera obrar en dita fabrica» ${ }^{59}$. Rafael Boladeras, soguero de Sallent, arrendaba los frutos de dos viñas porque necesitaba dinero para sus urgencias «y en particularment pera comprar cabals pera fer correr la fábrica de cotó» ${ }^{60}$. Hay algunos individuos que se endeudaban, vendían o se desprendían temporalmente de sus propiedades (la complementariedad con la agricultura no puede perderse de vista incluso en estos fabricantes) para poner en marcha las nuevas fábricas.

Algunos inventarios de estos años nos dan pistas sobre cómo eran estos primeros fabricantes. En el año 1805 una mujer tomaba inventario de los bienes de

\footnotetext{
${ }^{56}$ La venta a carta de gracia era una venta con derecho a recuperar lo que se había vendido pasado un tiempo. En la práctica era un préstamo.

57 «para una fábrica de algodón que espera poner en la casa que posee en la presente villa y calle llamada del Cos» AHCM, Not Ferrusola, 1803, fol. 16, 22-I.

${ }^{58}$ AHCM, Not Ferrusola 1806-1807, fol. 116 (1807).

${ }^{59}$ AHCM, Not. Ferrusola 1803, fol. 98, 28-III: «por la fábrica que ha construido para colocar los instrumentos de algodonero y satisfacer el importe de las máquinas que ha plantado en dicha fábrica y emplear lo restante para comprar algodón para obrar en dicha fábrica».

${ }^{60}$ AHCM, Not. Camps 1804, fol. 35, 22-I: «y particularmente para conseguir capitales para hacer funcionar la fábrica de algodón».
} 
su marido Valentí Mas, cordonero. No tenían casa. Sus bienes eran dos telares de cordonero con todo lo necesario para su funcionamiento, un torno, una máquina de hilar algodón y una arroba de restos de algodón ${ }^{61}$. Muestra el inicio de la transición de una actividad textil a otra, pero sabemos poco más. En el año 1810, la viuda de Anton Vilaseca, fabricante de algodón y segundón de una masía de un pueblo vecino inventariaba una casa, dos urdidores, tres máquinas de hilar -dos de 60 husos y una de 100-, tres tornos para hacer mecha, dos telares, siete libras de algodón hilado, 18 libras de algodón cardado para hilar y la prensa para prensar las piezas ${ }^{62}$. Empezamos a encontrarnos con lo que será la fábrica típica de Sallent hasta los años cincuenta: algodón que se carda fuera -en las fábricas que utilizan energía hidráulica-, tornos que convertían en mecha el algodón cardado, máquinas de hilar, urdidores y telares para tejer las piezas y una prensa para prensarlas. El hilado y el tejido estaban integrados, sólo el cardado se realizaba fuera.

En el año 1813 el inventario de Maurici Comas, fabricante de algodón, recogía una situación parecida: nueve máquinas de hilar, once tornos, cuatro telares y una máquina de cardar. Tenía además una bodega con varias botas y dos viñas de su propiedad. En este caso existía también una máquina de cardado, suponemos que manual, pero éstas irán desapareciendo en beneficio de las fábricas hidráulicas ${ }^{63}$. Finalmente tenemos el inventario de Bernat Escayola del año 1825, según el cual tenía una casa a censo, ocho máquinas de hilar -tres de cien usos y las otras sencillas-, seis telares con sus tornos, una prensa, y entre sus deudas se encontraban 120 libras que debía pagar a Pere Montanyà por el cardado del algodón ${ }^{64}$. Por último, en el año 1839 Anton Soldevila, fabricante de algodón, tenía trece máquinas de hilar de 120 husos con sus tornos, doce telares, una prensa, un saco de algodón y un fardo en piezas tejidas, y además tenía «algunos fardos de piezas en varios comisionistas de Barcelona de los cuales se ha recibido algunos sacos de algodón y algunos dineros» ${ }^{65}$. La fábrica era un poco más grande, situada en los bajos de la casa, con máquinas de hilar que habían llegado a sus posibilidades máximas -120 husos- y una estructura productiva basada en que el fabricante compraba el algodón en Barcelona, lo tejía y vendía las piezas a través de comisionistas que pagaban a veces en algodón.

Este tipo de fábrica alcanzó su máxima difusión en la década de los años treinta del siglo XIX. A. García Balañá (2001, p. 425) aporta datos del Subsidio de Co-

\footnotetext{
${ }^{61}$ AHCM, Not. Camps 1805, fol. 168, 23-V.

${ }^{62}$ AHCM, Not. Ferrusola 1808-1811, fol 25 (1810).

${ }^{63}$ AHCM, Not. Camps 1813, fol. 102, 18-V.

${ }^{64}$ AHCM, Not. Camps 1825, fol 72, 5-III. Como veremos más adelante, Pere Montanyà tenía arrendada una parte de la fábrica de Cal Torres movida con energía hidráulica, en la que cardaba el algodón.

${ }^{65}$ AHCM, Not. Cerarols 1839, fol. 67, 10-III.
} 
mercio del año 1833 de Sallent. Este año declaraban 90 contribuyentes que tenían máquinas de hilar y cardar. Según sus cálculos había 346 bergadanas y según las contribuciones había 10 talleres de siete a 13 máquinas -87 del total-, 36, entre cuatro y seis -164 del total- y 38 entre una y tres -83 del total. Esto daba una media de 3,97 máquinas por taller, lo que indica el carácter modesto de estas instalaciones. Los seis mayores contribuyentes solo tenían 12 bergadanas, pero controlaban las 21 máquinas de cardar. Y éste es un elemento fundamental: el cardado se hacía fuera de los pequeños talleres.

\subsection{La energía hidráulica para el cardado del algodón}

El interés por la energía hidráulica en Sallent vino de la necesidad de mecanizar el proceso de cardado. En la villa había instalaciones antiguas que aprovechaban las aguas del Llobregat, de las que era relativamente fácil derivar pequeños canales para conseguir los saltos necesarios para cardar el algodón. Aunque el caudal del Llobregat daba para mucho más, las similitudes con Berga eran grandes: apenas había coste de instalación por la fuerte pendiente del río a su paso por Sallent y de la riera de Metge por Berga, y el trabajo de infraestructuras más importante ya estaba hecho. La única diferencia con Berga era que en Sallent fue posible reconvertir estas primeras instalaciones en fábricas de hilados y tejidos de algodón.

La deducción de que eran instalaciones para cardar algodón se puede hacer a base de pequeñas noticias. En el subsidio de comercio del año 1833 aparecen seis contribuyentes -los que tienen las fábricas de río-, que poseen las 21 máquinas de cardar algodón que funcionaban en el municipio. Es en esta estadística donde se ve la relación más clara ${ }^{66}$.

En una concordia en la fábrica del Salt Jussá del año 1807 se escribe que los molineros entrarían en las pérdidas o ganancias que dieran las máquinas de cardar algodón de la sociedad ${ }^{67}$. En el año 1814 se nombra a Jaume Xipell y Coll, panadero, como «encargado de la casa y fábrica con sus máquinas de preparar y cardar algodón». En el año 1815 entraba en esta fábrica Pere Montanyá, el cual aportaba tres máquinas de cardar que tenía en uno de los locales ${ }^{68}$. Este mismo año se arrendaba una de las naves: «damunt la estancia o quadra en la qual los arrendadors tenen fa alguns anys a esta part corrents sas maquinas de cardar cotó», y en el año siguiente se renovó el arrendamiento y se especificaba «dueños de aquella fabrica de cardar» ${ }^{69}$.

\footnotetext{
66 Véase García Balañá (2001, p. 426).

${ }^{67}$ AHCM, Not. Ferrusola, 1806-1807, fol. 39-40, 9-I-1807.

${ }^{68}$ AHCM, Not. Vilacendra 1815, fol. 5, 4-I.

${ }^{69}$ AHCM Not. Vilacendra 1815, fol. 167, 30-VII y Not. Camps 1816, fol. 158, 4-VIII.
} 
En el año 1816, en una fragua reconvertida en fábrica, Manuel Solá, arriero de Sallent, vendía por cuatro años a un comerciante de Balsareny, la sexta parte del beneficio de dos máquinas de $\operatorname{cardar}^{70}$. En el 1818, Pere Pedragosa arrendaba «la quarta part a ell corresponent dels lucros y ganancias que resultaran de aquellas dos maquinas de cardar cotó que van corrents per medi del aigua ${ }^{71}$. Una cuadra de la fábrica de Cal Torres era alquilada en el año 1829 a Pere Montanyá i Xipell para hacer funcionar las máquinas de cardar algodón que tenía con otros socios. Y en un inventario de un socio de la fábrica Vella -Ramon Serra- aparece la referencia a «varios subjectes que cardaren cotó en las maquinas de cardar de la mateixa societat la quantitat de 4 mil y pico de lliuras» ${ }^{72}$.

Otra forma de mostrar que eran fábricas dedicadas fundamentalmente al cardado del algodón la proporcionan pequeñas noticias de deudas entre los hiladores de bergadanas y los que poseían las instalaciones hidráulicas. En el año 1812 Joan Oller, galonero de Santpedor reconocía deudas a Tomas Viladomiu y Cia de Sallent "provenients y resultant de cotó que se li ha entregat a dit otorgant en diferents ocasions, y part de haverli dit Tomas Viladomiu y compañía cardat

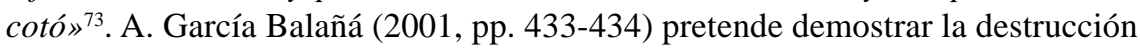
de esta red de hiladores y tejedores de bergadana a partir de los años cuarenta del siglo XIX, y el mecanismo son las deudas contraídas por los hiladores con los cardadores de algodón que se habían convertido en los que financiaban su capital circulante. Recojo, como ejemplo, algunas citas textuales: «per los treballs de cardarme cotó en la sua fabrica que tenen y posseheixen en la plasseta de Sant Bernat de esta dita Vila», "per cardar-li cotó», "per cotó cardat», Salvador Vilarmau debía a Tomas Viladomiu y Cia «de cardar cotó» y así sucesivamente.

Aunque los datos son fragmentarios, todos apuntan a lo mismo: en el modelo de la bergadana se utilizó la energía hidráulica para cardar el algodón necesario que alimentaba la red de hiladores locales, no para mover máquinas de hilar. Pero fue el cardado del algodón el que dio un carácter estratégico a los fabricantes: suministraban la materia prima, hacían la primera elaboración y financiaban el capital circulante de los hiladores/tejedores, que pasaba necesariamente por sus manos. Esta hegemonía les situó en una posición ventajosa en el momento de la transición a otra tecnología que empezó a producirse en el año 1830, cuando Joan Vilaregut, después de haber estado un tiempo residiendo en Inglaterra, encontró en Sallent -un tío suyo residía allí desde 1799- el lugar adecuado -la fábrica de Cal Torres- para instalar las primeras mules de hierro y los primeros telares mecá-

\footnotetext{
${ }^{70}$ AHCM, Not. Camps 1816, fol. 49, 16-III.

${ }^{71}$ AHCM, Not. Vilacendra 1818, fol. 274, 16-IX.

${ }^{72}$ AHCM, Not. Cerarols 1844, fol. 258, 22-VIII.

${ }^{73}$ AHCM, Not. Camps 1812, fol. 55, 25-II.
} 
nicos ${ }^{74}$. A partir de aquel momento todas las fábricas de río iniciaron un proceso de transformación que acabaría con el viejo modelo de la bergadana ${ }^{75}$. En el Cuadro 9 hemos recogido la cronología de este cambio que se produjo entre 1830 y 1845.

\section{CUADRO 9}

\section{FÁBRICAS DE RÍO DE SALLENT EN EL AÑO 1850} Y FECHAAPROXIMADA DEL CAMBIO TÉCNICO

\begin{tabular}{|l|c|c|c|c|c|c|}
\hline \multirow{2}{*}{ Fábricas* } & \multirow{2}{*}{$\begin{array}{c}\text { Año de } \\
\text { fundación }\end{array}$} & \multicolumn{4}{c|}{ Maquinaria en 1850 } & Año del \\
\cline { 5 - 7 } & c.v. & continuas & mules & telares & cambio \\
\hline José Esteve (Cal Ramon) & 1815 & 10 & & 1.128 & & 1845 \\
\hline Viladomiu y Pedragosa & 1815 & 13 & & 1.680 & 2 & 1830 \\
\hline Juan Vilaregut & 1816 & 55 & & 5.640 & 160 & 1830 \\
\hline Juan Mas y Cia. & 1808 & 55 & 28.800 & 2.640 & 60 & 1839 \\
\hline Serra, Claret y Cia. & 1808 & 40 & 1.240 & 1.980 & 2 & 1839 \\
\hline Prat, Valls y Cia. & $1818 ?$ & 18 & & 2.160 & 49 & 1839 \\
\hline Font Pons y Cia. & $1820 ?$ & 24 & & 3.000 & 60 & 1845 \\
\hline
\end{tabular}

Fuentes: Graell (s.a.) y Ferrer i Alòs (en prensa-a).

Notas:

* Falta una fábrica en esta lista: la de Xipell y Cia, en la presa del Cappelat.

** Los nombres que aparecen en la relación se refieren a los propietarios de las fábricas en 1850, no necesariamente a quienes las fundaron.

${ }^{74}$ Hoy sabemos por los trabajos de Solá Montserrat (2001) que Joan Vilaregut era un destacado liberal que estuvo refugiado en Londres en los años veinte, lo que le permitió conocer los avances de la industria textil inglesa aumentando su deseo de implantarlos en Cataluña. La fórmula que se utilizó era importar maquinaria y construir fábricas adecuadas para la misma y, por ello, se alió con Bonaplata en el año 1829. Joan Vilaregut quiso probar (no sabemos hasta qué punto de forma consciente) los dos modelos posibles a su regreso a Cataluña: en Sallent probó las mules de hierro y los telares mecánicos movidos por energía hidráulica (para ello arrendó la fábrica de Cal Torres y construyó una rueda hidraúlica en el año 1830) y en Barcelona probó la misma maquinaria pero movida a través de la máquina de vapor en el año 1833 asociado con Bonaplata y Rull (Nadal, 1983). Esta dualidad no ha sido suficientemente resaltada y nos indica que Joan Vilaregut fue el precursor de la renovación de la industria textil en el interior.

${ }^{75}$ Vid. Ferrer i Alòs (en prensa-a). 
El hilado del algodón y los tejidos de empesa se convirtieron en una oportunidad a finales del siglo XVIII. Paraires, comerciantes, artesanos, segundones de masías, a menudo modestos, se interesaron por la nueva actividad y adquirieron con capitales modestos máquinas de hilar de husos múltiples y telares manuales, algunos quizá reconvertidos de la antigua tejeduría de lana. Esta estructura, enormemente flexible, estaba directamente conectada con Barcelona, donde la red se aprovisionaba de algodón y vendía las empesas en crudo para ser estampadas. Las características de este desarrollo tenían mucho que ver con una tradición de diversificación de actividades productivas y de aprovechamiento de oportunidades que se realizaba con capitales modestos y, en este sentido, es posible entender el éxito de las bergadanas, que no necesitaban excesivo capital fijo y podían instalarse en cualquier parte. Fueron las demandas de algodón cardado de esta red de pequeños productores las que provocaron el interés por los establecimientos hidráulicos del río Llobregat, y los mejor situados en aquella red o los que habían tenido la suerte de poseer tierras o derechos sobre las aguas formaron sociedades para cardar algodón. La asociación se entiende más como una forma de compartir riesgos que como una estrategia productiva conjunta, ya que cada socio hacía funcionar las máquinas durante un tiempo. El resultado fue un proceso de fragmentación de estos primeros establecimientos hidráulicos.

Con el tiempo, los cardadores de algodón tuvieron una posición central en la estructura productiva, ya que convirtieron en dependientes a parte de los hiladores mediante los préstamos de algodón cardado. Asimismo, las capacidades energéticas del río Llobregat posibilitaban la reconversión de las fábricas para cardar algodón en fábricas de hilados con mules de hierro o selfactinas, a diferencia de Berga donde no era posible por el escaso caudal de la riera de Metge, y esto es lo que hicieron los socios de las fábricas de Sallent aliándose con otros de Manresa o Barcelona. La red de bergadanas y tejidos manuales de Sallent sucumbió lentamente y sus «fabricantes» entraron en las nuevas fábricas como hiladores o como cuadros medios -mayordomos o directores- de la industria textil ${ }^{76}$.

\section{EL MODELO DE LA CONTINUA EN MANRESA}

En el año 1801 se instalaron en Manresa las primeras continuas de hilar. Fue en este año cuando Simó Dalmau, Andreu Martí y Martí Codina, típicos comerciantes del siglo XVIII dedicados a los curtidos, a la seda, a los negocios vitícolas y a arrendamientos de todo tipo, bien asentado socialmente el primero y en pro-

${ }^{76}$ Vid. García Balañá (2001, pp. 394-475). 
ceso de ascenso social los dos últimos, junto con Pablo Serrano, de Madrid, maquinista capaz de construir las nuevas máquinas, empezaron a buscar en el Torrent de Sant Ignasi un lugar para instalar las primeras continuas ${ }^{77}$. El torrente, con mucho desnivel y un caudal garantizado por los sobrantes de las aguas de la acequia de la ciudad, permitía aprovechamientos hidráulicos modestos con poca infraestructura, y fue allí, en lo que sería la futura fábrica de Cal Serrano, y más abajo, en las Fontetes, donde los cuatro socios instalaron las dos primeras fábricas mecanizadas de la ciudad movidas con energía hidráulica. Todo parece indicar que, para los socios manresanos, era un negocio más en sus prácticas comerciales.

De esta primera compañía tenemos un inventario levantado en el año 1806 con motivo de la división de la sociedad en dos partes, de tal manera que una de las fábricas fue para Pablo Serrano y Andreu Martí y la otra para Simó Dalmau y Martí Codina ${ }^{78}$. No sólo podemos conocer la maquinaria de las fábricas, sino los resultados de cinco años de explotación.

Empecemos por el capital. Según el último balance realizado antes de la división el 30 de octubre de 1804, el capital era de 43.114,3 libras repartido en cuatro acciones de 10.778,55 libras. El día 31 de marzo de 1806, cuando se cerró el balance para proceder a la división de la sociedad, el valor líquido era de 80.658,6 libras, es decir que, en año y medio, cada socio había obtenido 9.386,05 libras de beneficios, lo que significa un $61 \%$ anual. No es de extrañar que, con esta rentabilidad, en Manresa y en estos años surgieran distintas iniciativas para hilar algodón a la inglesa.

Las dos fábricas, en el momento de la disolución, contaban con 37 máquinas inglesas -valoradas en 500 libras cada una- y doce cardadoras, trece «manuares» y doce mecheras como maquinaria auxiliar. Se complementaba con 32 máquinas sencillas, seguramente para la producción de tramas -27.891 libras. Toda la maquinaria suponía el 34,6\% del balance, el 31,9\% era el capital circulante -25.712,25 libras- y el 33,5\% correspondía a edificios e instalaciones -27.055,35 libras. Estas cantidades eran muy superiores a los capitales que se necesitaban para poner en marcha una fábrica de indianas, lo que nos indica que quienes pusieron en marcha una fábrica de continuas tenían un origen social muy distinto a los que ponían en marcha las bergadanas en Sallent.

\footnotetext{
${ }^{77}$ Hoy sabemos que Pablo Serrano fue el responsable de la construcción de las primeras máquinas continuas en Barcelona en el año 1793, encargadas por fabricantes de Barcelona y Olot que apostaron por ellas y aunque no puede establecerse una relación directa, todo hace pensar que Serrano conocía las máquinas por su participación en la Real Fábrica de Algodón de Ávila. Véase Martín García (1989) y Thomson (2003a). Cuando acabó su relación con Torroella y Serra, empezó una nueva relación comercial con los comerciantes manufactureros de Manresa, formando una sociedad que duraría hasta el año 1806. Desde entonces Pablo Serrano residió en Manresa, donde tenía una fábrica que llevaba su nombre en el Torrent de Sant Ignasi.

${ }^{78}$ AHPB, Not. Foch Broguetas 1806, fols 203-218, 23-VI.
} 
La coexistencia de máquinas inglesas y máquinas sencillas hace que se distinga claramente entre el algodón procedente de unas o de otras: "cotó vermell maquina senzilla acabat», «inglés sense ninguna operació», «maquina senzilla sense ninguna operació»... Es decir, eran tipos de hilado que incluso tenían distinto precio: el inglés a 52,5 sueldos la libra de algodón hilado y el de máquina sencilla a 45 sueldos. Los algodones que se hilaban procedían mayoritariamente de Pernambuco y en parte de Cumaná, y la venta de algodón hilado se hacía mayoritariamente en Barcelona a través de Casa Graell. En el año 1806 esta casa tenía género por valor de 19.065 libras, de cuya cantidad 13.377 libras «dehuen varios de Barcelona» ${ }^{79}$.

Tenemos datos de otra fábrica, la fábrica de Joan Baptista Soler ${ }^{80}$. En el año 1815 -y no es el primer contrato- se firmó una sociedad por seis años entre Josep Ignasi Soler -7.686,5 libras, de ellas 2.500 libras correspondientes a la servidumbre de aguas-, Teresa Font y su sobrino Francesc Obiols -6.588 libras-, Marianna y Josep Soler Espluga -4392 libras- y Manuel Comellas -4392 libras. La sociedad se denominaba Soler, Font, Soler y Comellas. Era Joan Ignasi Soler quien cuidaba de la marcha de la fábrica, si bien para llevar los libros y otras tareas se iban turnando ${ }^{81}$.

Tenemos la suerte de poseer tres balances-inventarios de esta fábrica, todos ellos muy detallados, que nos permiten conocer la maquinaria, en qué estaba invertido el capital y dónde se colocaban los géneros ${ }^{82}$. El capital fijo y capital circulante ascendía a 33.714 libras, una cantidad muy superior a la de las sociedades de Sallent, pero modesta con respecto a los grandes capitales de las compañías sederas. Terreno, fábrica y conducción de agua ascendían al 42\% del capital aunque nos parece un poco elevada la valoración de los derechos de agua-, la maquinaria al $28 \%$ y el capital circulante suponía solo el $29,8 \%$ del total, unas cifras bastante parecidas a las fábricas de Dalmau, Codina, Martí y Serrano que hemos visto más arriba.

Estos balances confirman que, en estos primeros años, la rentabilidad de la actividad fue muy elevada. Entre 1811 y 1813 -en plena guerra del francés- el beneficio sobre capital ascendió al 15\% anual; entre 1813 y 1814 sumó el 3,9\%,

${ }^{79}$ Not. Foch Broguetas 1806, fol. 86 y ss., 23-VI-1806, AHPB.

${ }^{80}$ Hijo heredero de una importante familia de curtidores del siglo XVII y veleros en el siglo XVIII, formando parte de una de las sociedades más importantes de la ciudad (Ferrer Alos, 1983).

${ }^{81}$ Lligall Soler, AHCM. Los otros socios eran galoneros que necesitaban algodón hilado para sus producciones de cintas y otras menuderías de seda. Eran socialmente más modestos que la familia Soler, pero pertenecían a este grupo de sederos dinámicos de finales del siglo XVIII.

${ }^{82}$ En parte han estado estudiados en Ferrer i Alòs (1987, pp. 374-378), por lo que nos remitimos a esta publicación y nos vamos a fijar únicamente en aspectos que allí no se recogían. 
una cifra modesta, aunque hay que tener en cuenta que se estaba en pleno período bélico, y de 1814 a 1818, el 20,4\% anual ${ }^{83}$. Estos beneficios permitían plantearse nuevos retos: así, algunos socios de esta compañía construirán una fábrica por su cuenta en Navarcles en el año $1818^{84}$.

En la partida de créditos de los balances de la fábrica constan los particulares que deben una cantidad, lo que permite aproximarse a quiénes eran sus clientes. Muy pocas veces se nos indica el lugar de origen de los mismos - «Josep Castells de Igualada», «Andreu Lluciá de Vic», «Jaume Puig de Cardona», «Josep Bosch de Navarcles»-, aunque parece deducirse que el algodón hilado se vendía en las zonas algodoneras próximas que hilaban tramas y tenían problemas con las urdimbres. También los propios socios de la compañía eran clientes -en el año 1813 Josep Font y Novas debía 1.279,35 libras; en el año 1814, Josep Font y Novas 1.513 libras, Josep Soler y Esplugas, 855,8 libras y Manuel Comellas, 34,15 libras; en el año 1818, 667 libras para Josep Font y 361 para Josep Soler y Espulga-, lo que nos confirma que esta participación en las compañías era una de las maneras de asegurarse el suministro de algodón hilado para sus actividades de cintería; asimismo, aparece el nombre de representantes que venden hilados en la Mancha, Segorbe o Valencia y, finalmente, cabe señalar que los cinteros de la ciudad -Fruitós Fabres, Francisco Serramalera, Maurici Guitart, Mariano Sacristá, Magí Sanmartí, Maurici Ignasi Pons, etc.- compraban también algodón hilado a la fábrica ${ }^{85}$.

¿Cómo explicar la expansión de las fábricas de continuas en Manresa? Los altos beneficios obtenidos en la fábrica de las Fontetes servían de reclamo en una cultura de aprovechamiento de oportunidades, pero también ayudaba la incipiente crisis de los pañuelos de seda, las dificultades en el mercado americano y el incremento de la demanda de algodón hilado por parte de los galoneros y cinteros $\mathrm{y}$, muy pronto, por los antiguos tejedores de seda que se aventuraron en los tejidos de mezcla. En el Cuadro 10 se recoge la cronología de la puesta en marcha de las nuevas fábricas con tecnología de continuas.

Del cuadro se desprende que ocho de las fábricas de continuas fueron puestas en marcha antes de 1806 y tres en el año 1816, aunque en este período de tiempo se reconvirtieron dos fábricas de indianas y fueron divididas por lo menos cuatro. Seis de estas fábricas fueron construidas en el modesto torrente de San Ignacio por la facilidad de aprovechar el desnivel del mismo y cuatro en el Cardener, utilizando infraestructuras de antiguos molinos. Sólo la fábrica del Riu de Navarcles fue construida en un paraje en el que no había ninguna infraestructura anterior. Las necesidades energéticas eran todavía modestas.

${ }^{83}$ Véase Ferrer i Alòs (1987, p. 376).

${ }^{84}$ Vid. Ferrer i Alòs (1994b).

${ }^{85}$ AHCM, Legajo. Soler, Balances de la sociedad Soler, Font, Soler y Comellas de 1813, 1814 y 1818. 


\section{CUADRO 10}

\section{EXPANSIÓN DE LAS FÁBRICAS DE CONTINUAS EN MANRESA}

\begin{tabular}{|l|l|l|l|}
\hline \multicolumn{1}{|c|}{ Fábrica } & \multicolumn{1}{|c|}{ Río } & \multicolumn{1}{|c|}{ Año } & \multicolumn{1}{c|}{ Incidencias } \\
\hline Serrano & torrente & 1801 & $\begin{array}{l}\text { Pertenecientes inicialmente a la misma } \\
\text { compañía, ésta las repartió entre sus } \\
\text { socios }\end{array}$ \\
\hline de les Fontetes & torrente & 1801 & \\
\hline Pont de Fusta & Cardener & $1804^{*}$ & Desdoblada en 1817 \\
\hline Cots & Cardener & $1804^{*}$ & Desdoblada en 1822 \\
\hline Comdals & Cardener & 1804 & $\begin{array}{l}\text { Enemistados los socios, se la quedó } \\
\text { el que ofreció más por ella }\end{array}$ \\
\hline Molí del Serra (Navarcles) & Calders & 1805 & Desdoblada en 1829 \\
\hline de Maurici Pla & torrente & 1806 & Desdoblada en 1817 \\
\hline Joan Baptista Soler & torrente & 1806 & \\
\hline Argullol & torrente & $1815 ?^{* *}$ & \\
\hline de l’Arenys & torrente & $1807 ?$ & \\
\hline Barrera (Castellgalí) & Cardener & 1816 & \\
\hline Costa (Cardona) & Cardener & 1816 & \\
\hline del Riu (Navarcles) & Llobregat & $1816^{* * *}$ & \\
\hline
\end{tabular}

Fuente: Ferrer i Alòs (1999 y en prensa-a).

Notas: * Ambas fábricas operaban con la misma represa y canal.

${ }^{* *}$ Previamente había sido fábrica de indianas.

*** Construida por socios que se separaron de la Compañía de Joan Baptista Soler.

En algunos casos no parece que la formación de una sociedad tuviese como objetivo la producción colectiva de hilados de algodón, sino que era la forma menos arriesgada de participar en una actividad que, a diferencia de lo que se había hecho hasta entonces en que apenas existía capital fijo, requería una inversión importante en maquinaria y edificaciones. Debido a ello la producción se organizaba por meses y cada socio utilizaba las máquinas en el período que le correspondía, fabricando hilados para él o para venderlos a quien considerara oportuno. En la fábrica dels Condals puesta en marcha en el año 1804 se acordaba en el año 1812 «repartirse les existencies y credits de la mateixa fabrica y possehir y valerse de esta tres mesos continuos cada soci, podent en dit termini filar y treballar en ella com millor le aparega de sos propis comptes fins que se 
acabi la societat» ${ }^{86}$. Es decir, tres meses haría trabajar la fábrica un socio, y tres meses el otro socio por su cuenta y riesgo. Lo mismo ocurría en la fábrica del Riu de Navarcles, como se deducía del acuerdo entre un socio de la sociedad que tenía problemas económicos y un cordonero que invertía capital para ayudarle en el año 1826:

«per sos infortunis ha patit una decadencia notable en sos capitals de modo que acudint al pago de sos acreedors com es just, no li quedan los suficients per a treballar de son compte en lo temps que li toca en la fabrica de filats de cotó [...] en lo terme del lloch de Navarcles» ${ }^{87}$.

Las cláusulas de la asociación son muy interesantes porque muestran como estaba organizado el trabajo:

«que Soler tindra lo encarrech de comprar o fer comprar a costas corresponents dels dos tot lo cotó fluix se necessitia per filar cada mes que li toquia de filar, cuydar de tot quan convinguia lo mateix que fos per si sol [...] Que finit lo mes de filar Soler entregara a Sanmartí la mitat de fil de cada quantitat se haura filat» ${ }^{88}$.

Cada socio utilizaba la fábrica durante un mes y el algodón servía para que funcionaran otras producciones -cintas y tejidos de mezcla-, y la acumulación en el primer tercio del siglo XIX se dio en estas actividades más que en la hilatura.

El fin de este modelo fue algo más tardío que el de las bergadanas, seguramente por el coste de las máquinas. En el proceso de liquidación de la fábrica Prat, Badia, Fuster y Torrents se escribía que «atendido a que dicha sociedad se ocupó en el ramo de la hilatura de algodón hasta el año 1843, en cuya época siendo pocas o más bien mesquinas las utilidades que producía este ramo de industria ya por el mal estado de la maquinaria ya también por el muy antiguo sistema de ellas» ${ }^{89}$. Es un texto muy claro sobre lo que estaba pasando, e indica que era un modelo totalmente agotado. Pascual Madoz, en el artículo dedicado a la industria de Manresa, aporta datos que permiten ver el estado de las fábricas a partir por lo menos de 1843 y el tipo de maquinaria que utilizaban (Cuadro 11) ${ }^{90}$.

A pesar de que los datos son algo incompletos puede verse cómo en la mayoría de las fábricas predominaban las máquinas inglesas, aunque en algunas ya se había empezado el proceso de sustitución por mules o máquinas francesas. El

${ }^{86}$ AHCM, Not. Mas 1812, fol. 696, 1-XII.

${ }^{87}$ AHCM, Not. Mas 1826, fol. 486, 17-XII.

${ }_{88}$ Ibidem.

${ }^{89}$ Not. Moragas 1853, fol. 193, 18-V-1853, AHPB.

${ }^{90}$ En un momento de la relación de fábricas se especifica «en la que había hasta mediados de 1843» lo que quiere decir que la relación es posterior a esta fecha. 


\section{CUADRO 11}

\section{MAQUINARIA DE LAS FÁBRICAS CON HILATURA DE ALGODÓN EN MANRESA, CA. 1845}

\begin{tabular}{|l|c|c|c|c|}
\hline & $\begin{array}{c}\text { Tipo de } \\
\text { maquinaria }\end{array}$ & $\begin{array}{c}\text { Producción } \\
\text { diaria de } \\
\text { hilo (libras) }\end{array}$ & $\begin{array}{c}\text { Números } \\
\text { del hilo }\end{array}$ & $\begin{array}{c}\text { Tipo } \\
\text { de hilo }\end{array}$ \\
\hline Río Cardener: & \multicolumn{5}{|l|}{} \\
\hline Prat, Badia y Fuster (1804) & 40 mq. inglesas & 200 & 20 al 30 & \\
\hline Vidal, Balaguer, Perera (1804) & 50 mq. inglesas & 240 & 20 al 40 & urdimbre \\
\hline Miquel Cots y Enrich (1804) & 45 mq. inglesas & 170 & 20 al 25 & urdimbre \\
\hline Francisco Sacristá (1804) & 14 mq.francesas & 150 & 15 al 25 & trama/urd. \\
\hline Torrent de Sant Ignasi: & 12 mq. inglesas & 60 & 18 al 26 & urdimbre \\
\hline Maurici Pla (1806) & mq. francesas & & & \\
\hline Prat, Badia y Fuster (1806) & 8 mq. francesas & 104 & 12 al 28 & \\
\hline Llogari Serra (1806) & 14 máquinas & 60 & 12 al 24 & \\
\hline Joaquín Argullo & 20 mq. inglesas & & 20 al 40 & urdimbre \\
\hline Pablo Serrano (1801) & 30 mq. inglesas & 150 & 20 al 30 & urdimbre \\
\hline Mariano Batlles (1801) & $\begin{array}{l}15 \text { mq. inglesas, } \\
4 \text { mq. francesas }\end{array}$ & 100 & 20 al 35 & tramas \\
Mariano Batlles & & & \\
\hline
\end{tabular}

Fuente: Madoz (1845-1859), voz «Manresa».

cuadro también confirma que las máquinas inglesas hilaban sobre todo urdimbres, mientras que las francesas eran polivalentes. A mediados de la década de los cincuenta las viejas continuas habían desaparecido de todas las fábricas.

La industria de la seda que se había desarrollado en el siglo XVIII había posibilitado una acumulación de capital que permitió que algunos decidieran invertir, formando sociedades para minimizar el riesgo, en una actividad industrial totalmente nueva, que implicaba construir una fábrica, aprovechar una energía hidráulica y poner en marcha máquinas asimismo nuevas. Las continuas hilaban urdimbres necesarias para complementar las tramas de las bergadanas, pero también para satisfacer una demanda local de cinteros y de tejedores de tejidos de mezcla. En realidad, muchos de los socios de las fábricas tenían sus propios talleres de cintería, y el negocio no estaba en la venta de los hilados, sino en los tejidos elaborados. Todo parece indicar que esta hilatura era la que más se adaptaba a la demanda local. 


\section{CONCLUSIÓN}

La modernización de la industria algodonera en Cataluña fue un proceso complejo y no lineal. A menudo se ha fijado la fecha de 1833, momento en que se puso en marcha la fábrica Bonaplata, como el punto de arranque de la industria moderna catalana, aunque en los últimos años se han empezado a establecer continuidades con la etapa final del siglo XVIII ${ }^{91}$. Sin embargo, una lectura de los datos estadísticos que aporta el Diccionario de Madoz por partidos judiciales sobre la industria algodonera catalana en el año 1841 y de otras fuentes permite señalar algo que los distintos autores que han trabajado en el tema no han apuntado: la existencia de tres geografías hiladoras que se corresponden con una determinada tecnología y con unas características productivas específicas. El hecho de no remarcar estas variables se debe, en parte, a considerar el territorio como homogéneo desde un punto de vista social y, como hemos pretendido argumentar, la variedad de tradiciones productivas es la que explica el desarrollo de una determinada tecnología.

La primera geografía hiladora se basó en la bergadana, un perfeccionamiento de la jenny y que fue introducida en Cataluña a finales de los años ochenta, extendiéndose como la pólvora por la Cataluña interior. Los partidos judiciales de Igualada, Berga, Vic, parte del de Manresa y del de Olot, concentraban la mayor parte de esta hilatura. Los talleres eran modestos, con tres o cuatro máquinas de hilar de 120 husos y entre seis y ocho telares, situados en las mismas casas de los fabricantes. Daban ocupación a pocos hombres y a una gran cantidad de mujeres y niños que complementaban así los ingresos de la unidad familiar. La productividad por huso era inferior a la de otras tecnologías y los salarios estaban también muy por debajo de los de la zona de mules. Las máquinas producían sobre todo tramas -las urdimbres procedían de las zonas de continuas o mules-, hilados bastos de números bajos, y se tejían sobre todo empesas que se utilizaban para estampar en Barcelona. El algodón procedía de Barcelona y el mercado de empesas también se realizaba en la Ciudad Condal. El único proceso mecanizado era el cardado.

Las informaciones que hemos aportado sobre Sallent y en parte sobre Berga muestran que la tecnología se difundió a gran velocidad gracias al proceso de copia de los carpinteros y cerrajeros locales, pero sobre todo porque encontró un espacio productivo acostumbrado a vivir de diversas especializaciones. Antiguos artesanos, campesinos, paraires, etc. compraron nuevas máquinas de hilar y pusieron en marcha la fabricación. Una tecnología más cara no se hubiera expandido de la misma manera. Las ventajas en los costes -complementariedad entre el trabajo masculino en la agricultura y el de las mujeres y niños en la actividad indus-

${ }^{91}$ Véase Sánchez Suárez (2000a). 
trial-, la especialización en tejidos baratos y el hecho de que la producción de tramas no estaba bien solucionada en otras tecnologías hicieron posible que esta geografía subsistiera sin muchos problemas hasta $1830^{92}$.

La segunda geografía de la hilatura es la que utilizaba la continua como tecnología hiladora, mucho más intensiva en capital, que sólo producía urdimbres y que era accionada necesariamente mediante energía hidráulica. El capital fijo de la instalación era muy elevado, tanto por el precio de las máquinas como por el coste del edificio, salto de agua y mecanismos de transmisión. La mayor concentración de continuas se produjo en Manresa y en algunos pueblos de los alrededores $78,6 \%$ de las máquinas. Las continuas eran más productivas y utilizaban más varones y menos niños que las bergadanas, y los salarios eran intermedios entre la zona de bergadanas y la zona de mules. Las nuevas fábricas eran pequeñas y los costes de capital fijo se reducían, bien instalándose en zonas con pocas necesidades de infraestructura, bien compartiendo un salto de agua entre varias fábricas. El número de socios por cada sociedad era muy elevado, lo que indica que se intentaba reducir el riesgo. Los citados socios solían ser comerciantes manufactureros, tejedores de velos y cinteros bien situados.

Los beneficios fueron muy elevados y ello se convirtió en un reclamo para poner en marcha nuevas fábricas. Es difícil conocer las razones del éxito de esta tecnología en Manresa. Los comerciantes manufactureros y tejedores de velos más o menos acomodados disponían de capitales y estaban acostumbrados a diversificar inversiones. Los problemas con el mercado americano llevaron a la crisis de la producción sedera de la ciudad y las demandas de algodón eran crecientes por parte de los cinteros que se especializaban en la producción de vetes -cintas de algodón- y de los tejedores que empezaban a probar los tejidos de mezcla de más calidad que las empesas. En realidad hay fábricas que funcionaban como complemento de las producciones locales -cada socio la hacía funcionar durante un tiempo- y para abastecer las demandas locales y de urdimbres que pudieran tener las zonas de bergadanas próximas. En los años cuarenta estas fábricas habían entrado en crisis y no serán estos primeros fabricantes, sino los productores de cintas y de tejidos de mezcla, los que invertirán en las nuevas fábricas más modernas desde el punto de vista tecnológico.

La tercera geografía corresponde a la tecnología de la mule de madera y se desarrolló especialmente en los partidos judiciales de Barcelona, Mataró y Arenys de Mar. La mule es la máquina que entró más tarde en Cataluña, hilaba urdimbres y tramas y producía hilados más finos, de números más altos. La energía que se

92 Es necesario estudiar estos espacios desde la lógica propia del territorio. En estos momentos empezamos a conocer el caso de Sallent y de Berga gracias a los trabajos de Solá (1995, 1997, 2002), pero desconocemos totalmente lo que ocurrió en Igualada, uno de los partidos con bergadanas más importantes. 
utilizaba procedía de las caballerías. Las fábricas de hilar tenían más husos que en la zona de bergadanas -900 husos frente a 400-, la productividad por huso era más del doble, se daba trabajo a muchos más varones, a menos niños y a más mujeres, y los sueldos eran un $70 \%$ superiores a los vigentes en la zona de bergadanas. Las fábricas de tejidos solían ser independientes de las de hilados y tenían más telares -20 telares frente a 5/6 en la zona de bergadanas. La zona estaba especializada en producir tejidos de mezcla de más calidad que las empesas. La mule respondía mucho mejor a las necesidades de estas áreas porque producía hilados más finos, que servían tanto para urdimbres como para tramas ${ }^{93}$.

Las tres geografías hiladoras se complementaron durante unas cuantas décadas, hasta que la aparición progresiva de las nuevas tecnologías de la mule de hierro y, poco después, las selfactinas las hirieron de muerte. Las nuevas máquinas necesitaban otras fuentes de energía y muy pronto empezó una competencia entre la máquina de vapor y la energía hidráulica. En Manresa y en Sallent las antiguas fábricas se reconvirtieron y se construyeron de nuevo siempre al lado mismo de los ríos para aprovechar la energía hidráulica. En Barcelona la opción fue la construcción de grandes vapores, lo mismo que en Igualada, donde la falta de agua llevó a experimentar con el vapor en la propia ciudad o en Reus. Es el momento de la duda entre energía hidráulica y vapor, antes que las fábricas de río ganen la batalla. Son estas geografías las que explican que el proceso industrial catalán no fuera un fenómeno barcelonés y, a pesar de su disolución por los cambios tecnológicos, de ellas surgieron nuevos fabricantes, cuadros directivos, hiladores y tejedores que continuaron operando sobre el territorio. Las tradiciones productivas son muy importantes para entender la complejidad y peculiaridades del proceso de industrialización.

\section{FUENTES}

AHCM: Arxiu Històric de la Ciutat de Manresa

AHPB: Arxiu Històric de Protocols de Barcelona

\section{BIBLIOGRAFÍA}

Aspin, C. (1984): The Cotton Industry. Aylesbury: Shire Publications.

Benaul J. M. (1992): «Los orígenes de la empresa textil lanera en Sabadell y Terrassa en el siglo XVIII». Revista de Historia Industrial 1, pp. 39-62.

${ }^{93}$ Conocemos mucho menos la sociología de estas zonas. Sería interesante que se estudiara desde este punto de vista. Algunas sugerencias pueden encontrarse en García Balañá (2001). 
- (1995): «Cambio tecnológico y estructura industrial. Los inicios del sistema de fábrica en la industria pañera catalana, 1815-1835». Revista de Historia Económica XIII (2), pp. 199-227.

Benet Clará, A. (1988): «Sallent», en V.V.A.A., Història del Bages. Manresa: Parcir, pp. 221-284.

— (1989): «Les fargues d'aram i de filferro de Sallent al segle XVIII». Miscel.lània d'Estudis Bagencs 6, pp. 49-65.

Benson, A. P. (1983): Textile Machines. Aylesbury: Shire Publications.

Berg, M. y Bruland, K. E. (1998): Technological Revolutions in Europe. Historical Perspectives. Cheltenham-Northampton: Edward Elgar.

Catling, H. (1970): The Spinning Mule. Newton Abbot: David \& Charles Publishers.

Diccionario Geográfico Universal dedicado a la Reina por una sociedad de literatos. (18341835). Barcelona: Imp. de José Torner.

Ferrer i Alòs, L. (1983): «Genealogia de la família Soler i March. Aspectes socioeconòmics». Miscel.lània d'Estudis Bagencs 2, pp. 31-52.

- (1985): «Josep Pons i Enrich, industrial manresà i fundador de la colònia Pons de Puigreig». Dovella 15 (marzo), pp. 31-34.

- (1987): Pagesos, rabassaires i industrials a la Catalunya Central (s. XVIII-XIX). Barcelona: Publicacions de l'Abadia de Montserrat.

— (1994a): «La cintería en Manresa en el siglo XIX. Industrialización y pequeña empresa», en J. Nadal y J. Catalán (eds.), La cara oculta de la industrialización española. La modernización de los sectores no líderes (s. XIX-XX). Madrid: Alianza Universidad, pp. 225-267.

- (1994b): Les fàbriques de riu de Navarcles. Manresa: Centre d'Estudis del Bages.

- (1999): «Les primeres fàbriques i els primers fabricants a la Catalunya Central», en V.V.A.A., Doctor Jordi Nadal. La industrialització i el desenvolupament econòmic d'Espanya. Barcelona: Universitat de Barcelona, pp. 1038-1056.

- (en prensa-a): Genealogías de la industrialización. De la seda al algodón en la Catalunya Central. Barcelona: Publicacions de la Universitat de Barcelona

- (en prensa-b): «Notas sobre el reemplazo social en Catalunya. De artesanos a rentistas y vuelta e empezar (s. XVII-XIX)». Granada: Actas del VII Congreso de la ADEH.

FERRER VIDAL, J. (1874): Conferencias sobre el arte de hilar y tejer en general y especialmente sobre el de hilar y tejer algodón. Barcelona: Est. Tip. J. Jetus Roviralta.

Figuerola, L. (1849): Estadística de Barcelona en 1849. Barcelona: Imprenta y Librería Politécnica de Tomas Gorchs.

Fitton, R. S. (1989): The Arkwrights. Spinners of Fortune. Manchester: Manchester University Press.

Fontana, J. (1973): Cambio económico y actitudes políticas en la España del siglo XIX. Barcelona: Ariel.

— (1974): «Comercio colonial e industrialización: una reflexión sobre los orígenes de la industria moderna en Cataluña», en J. Nadal y G. Tortella (eds.), Agricultura, comercio colonial y crecimiento económico en la España contemporánea. Barcelona: Ariel, pp. 358-365.

García Balañá, J. (2001): «La fabricació de la fàbrica. Treball i política a la Catalunya cotonera (1784-1884)». Barcelona: Universitat Pompeu Fabra, tesis doctoral.

- (2004): La fabricació de la fàbrica. Treball i política a la Catalunya cotonera (17841874). Barcelona: Publicacions de l’Abadia de Montserrat. 
García Espuche, A. (1998): Un siglo decisivo. Barcelona y Catalunya (1550-1640). Madrid: Alianza Editorial.

GianNetTI, R. (1994): «Las representaciones de la innovación tecnológica en perspectiva histórica». Revista de Historia Industrial 6, pp. 31-46.

Graell, G. (s.a.): Historia del Fomento del Trabajo Nacional. Barcelona.

Guía de Forasteros en Barcelona y noticia de las fábricas de las cuatro provincias de Cataluña (1842). Barcelona: José Saurí.

IzARD, M. (1973): Industrialización y obrerismo: las Tres Clases de vapor. Barcelona: Ariel.

Jeremy, D. (1981): Tansatlantic Industrial Revolution: The difusion of Textile Tecnologies Between Britain and America, 1790-1830's. Cambridge, MA.: MIT Press.

LeAdBeAter, E. (1985): Spinning and spinning wheels. Aylesbury: Shire Publications.

Madoz, P. (1845-1850): Diccionario Geográfico Estadístico histórico de España y sus posesiones en Ultramar. Madrid: Est. Literario-Tipográfico de P. Madoz y L. Sagasti.

Maluquer de Motes, J. (1976): «La estructura del sector algodonero en Catalunya durante la primera etapa de la industrialización (1832-1861)». Hacienda Pública Española 38, pp. 133-148.

- (1994): «La gran transformació. Industrialització i modernització a la Catalunya del segle XIX», en V.V.A.A., Història Econòmica de Catalunya. La formació d'una societat industrial. Barcelona: Fundació Enciclopèdia Catalana, pp. 41-186.

Martín García, G. (1989): La industria textil en Ávila durante la etapa final del Antiguo Régimen. La Real Fábrica de Algodón. Ávila: Diputación Provincial de Ávila.

Midgley, T. (1981): The spinning Mule. An Account of the Life of it's Inventor. Samuel Crompton, 1753-1827. Bolton Metropolitan Borough: John Bentley.

NADAL, J. (1975): El fracaso de la Revolución Industrial en España (1814-1913). Barcelona: Ariel.

- (1983): «Los Bonaplata. Tres generaciones de industriales catalanes en el siglo XIX». Revista de Historia Económica I (1), pp. 79-95.

O’Brien, P., Griffiths, T. y Hunt, P. A. (1996): «Theories of Thecnological Progress and the British Textile Industry from Kay to Cartwright». Revista de Historia Económica XIV (3), pp. 533-556.

ОкиNо, Y. (1999): «Entre la llana i el cotó. Una nota sobre l'extensió de la indústria del cotó als pobles de Catalunya en darrer quart del segle XVIII». Recerques 38, pp. 47-76.

Oliva Ricos, B. (1999): Els orígens de la primera industrialització al rerepaís. Un cas emblemàtic: Vilassar i el capital comercial barceloní (1828-1875). Mataró: Caixa d'Estalvis Laietana.

Reddy, W. M. (1984): The Rise of Market Culture. The Textile Trade and French Society, 1750-1900. Cambridge y París: Cambridge University Press / Edition de la Maison des Sciences de l'Homme.

Ronquillo, J. O. (1851-1857): Diccionario de materia mercantil, industrial y agrícola, que contiene la indicación, la descripción y los usos de todas las mercancías. Barcelona: Imprenta de Agustí Gaspar / Imprenta de José Tauló.

RosenBerg, N. (1994): «Incertidumbre y cambio tecnológico». Revista de Historia Industrial 6, pp. 11-30.

Rosés, J. R. (1997): «La integración vertical en el sector algodonero catalán, 1832-1861», en S. López García y J.M. Valdaliso (eds.), ¿Qué inventen ellos? Tecnología, empresa y cambio económico en la España Contemporánea. Madrid: Alianza Universidad, pp. 249-280. 
SÁnchez SuÁrez, A. (1988): «De la Compañía de Hilados a la Comisión de Fábricas. El asociacionismo empresarial en Catalunya durante la crisis del Antiguo Régimen (17711820)», en V.V.A.A., II Congrés d'Història Moderna de Catalunya. Barcelona: Departament d'Història Moderna de la Universitat de Barcelona, pp. 385-394.

- (1989): «La era de la manufactura algodonera en Barcelona (1736-1839)». Estudios de Historia Social 48-49, pp. 65-114.

- (1992): «La indianería catalana: ¿̇mito y realidad?» Revista de Historia Industrial 1, pp. 213-232.

- (2000a): «Crisis económica y respuesta empresarial. Los inicios del sistema fabril en la industria algodonera catalana, 1797-1839». Revista de Historia Económica XVIII (3), pp. 485-525.

— (2000b): «Les berguedanes i les primeres màquines de filar», en J. Maluquer de Motes, (Ed.), Tècnics i tecnologia en el desenvolupament de Catalunya Contemporània. Barcelona: Enciclopèdia Catalana, pp. 161-175.

SAYRò, E. (1842): Industria algodonera de Cataluña. Madrid: Imprenta Nacional.

Serra, R. y Ferrer, L. (1985): «Un qüestionari de Francisco de Zamora (1789)». Estudis d'Història Agrària 5, pp. 159-207.

Serra, R. y Vilades, R. (1987): La colònia Pons de Puigreig (1875-1987). Berga: Ambit de Recerques del Berguedà.

SolÁ, A. (1995): «Indústria tèxtil, màquines i fàbriques a Berga». L'Erol 47, pp. 12-15.

— (1997): «Màquines tèxtils i lexicografia en la història de la llengua catalana. Notes entorn de la denominació de les primeres màquines de filar cotó a Catalunya (1786-1860)». Miscel.lània d'EStudis Bagencs 10, pp. 151-186.

— (2002): «Filar amb berguedanes. Mite i realitat d'una màquina de filar cotó», en V.V.A.A., La industria textil. Actes de les V Jornades d'Arqueologia Industrial de Catalunya. Barcelona: Enginyers Industrials de Catalunya, pp. 143-168.

- (2004): Aigua, indústria i fabricants a Manresa (1759-1860). Manresa: Centre d'Estudis del Bages.

Solá Montserrat, R. (2001): Joan Vilaregut i Alfabull. Industrial i progressista (Barcelona, 1800-1854). Barcelona: Publicacions de l'Abadia de Montserrat.

SOler Vilabella, R. (1911): Ensaig sobre la maquina catalana de filar cotó coneguda per Bergadana o Maxerina. Barcelona: J. Horta.

Thomson, J. (1994): Els orígens de la industrialització a Catalunya. El cotó a Barcelona (1728-1832). Barcelona: Edicions 62.

- (1998): «The Arrival of the First Arkwright Machine in Catalonia». Pedralbes 18, pp. 63-71.

— (2001): «La introducció de les màquines jenny a Barcelona (1784-1789): les primeres etapes en la creació d'una tradició de construcció de maquinària». Recerques 42, pp. 125-146.

- (2003a): «Olot, Barcelona and Avila and the Introduction of the Arkwright Technology to Catalonia». Revista de Historia Económica XXI (2), pp. 297-334.

- (2003b): «Transferring the Spinning Jenny to Barcelona: An Apprenticeship in the Technology of the Industrial Revolution». Textile History 34 (1), pp. 21-46.

- (2004) «Invention in the Industrial Revolution: the Case of Cotton», en L. Prados de la Escosura (ed.), Exceptionalism and Industrialisation: Britain and Its European Rivals, 1688-1815. Cambridge: Cambridge University Press, pp. 127-144. 
ToRras EliÁs, J. (1984): «Especialización agrícola e industria rural en Cataluña en el siglo XVIII». Revista de Historia Económica II (3), pp. 113-128.

- (1987): «Fabricants sense fàbrica. Estudi d'una empresa llanera d'Igualada (1726-1765)». Recerques 19, pp. 145-160.

Tunzelmann, G. N. von (1993): «Technological and Organizational Change in Industry During the Early Industrial Revolution», en P. O’Brien, y R. E. Quinault (Eds.), The Industrial Revolution and British Society. Cambridge: Cambridge University Press, pp. 254-283.

- (1995): Technology and Industrial Progress. The Foundation of Economic Growth. Aldershot: Edward Elgar.

VILAR, P. (1964-1968): Catalunya dins l'Espanya Moderna. Recerques sobre els fonaments econòmics de les estructures nacionals. Barcelona: Edicions 62.

Zamora, F. D. (1973): Diario de los viajes hechos en Cataluña. Barcelona: Curial. 